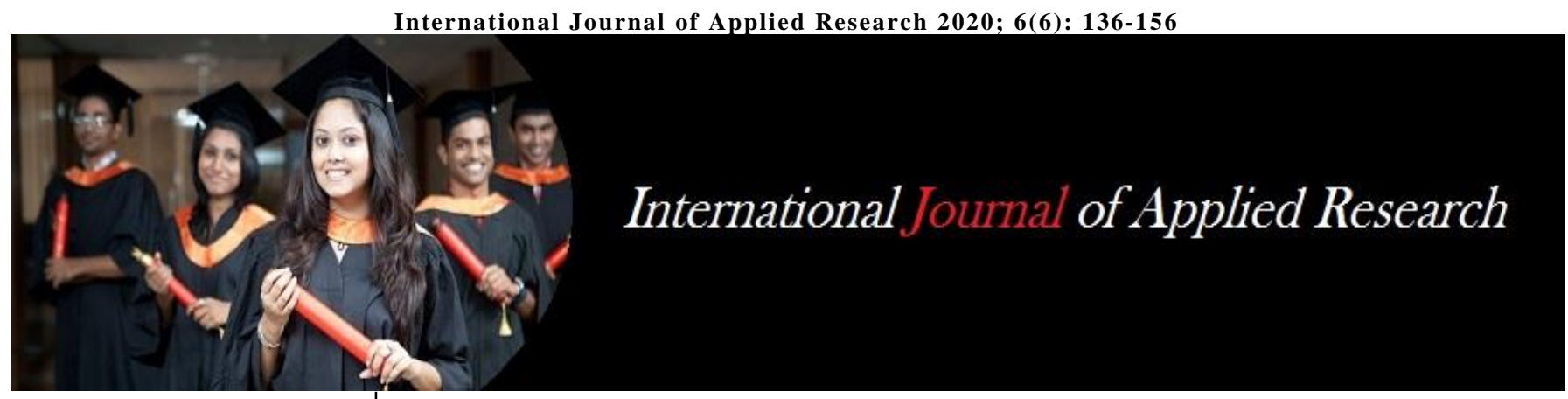

ISSN Print: 2394-7500 ISSN Online: 2394-5869 Impact Factor: 5.2 IJAR 2020; 6(6): 136-156 www.allresearchjournal.com

Received: 19-04-2020 Accepted: 21-05-2020

Vijaya Kumar P Department of Chemistry, Jawaharlal Nehru Technological University, Anantapur, Andhra Pradesh, India

Yadati Narasimha Spoorthy Research Scholar, Dept. of Chemistry, Sri Krishna Devaraya University, Anantapur, Andhra Pradesh, India

LK Rvindranath Professor, Dept. of Chemistry, Sri Krishna Devaraya University, Anantapur, Andhra Pradesh, India
Corresponding Author: Vijaya Kumar P Department of Chemistry, Jawaharlal Nehru Technological University, Anantapur, Andhra Pradesh, India

\section{Molecular docking, synthesis, characterisation and in vitro anti-mitotic evaluation of some novel pyrrole and pyrazole derivatives of purine}

\author{
Vijaya Kumar P, Yadati Narasimha Spoorthy and LK Rvindranath
}

DOI: https://doi.org/10.22271/allresearch.2020.v6.i6c.6777

\begin{abstract}
Hydrazinyl purine derivatives react with acetonyl acetone in presence of glacial acetic acid in alcohol form respective pyrrole derivatives. Hydrazinyl purine derivatives react with acetyl acetone in presence of catalytic amount of hydro chloric acid in water form respective pyrazole derivatives. The structures of these compounds have been established by ${ }^{1} \mathrm{H}$ NMR studies, IR studies and Mass data. This docking study explores the anti-mitotic activities of pyrrole and pyrazole derivatives of purine. The result from the docking study showed that pyrazole derivatives had excellent anti-mitotic activity that was comparable to the activity of abacavir.
\end{abstract}

Keywords: Hydrazinyl purine derivatives, acetyl acetone, acetonyl acetone, pyrrole and pyrazole derivatives, anti-mitotic activity, docking studies

\section{Introduction}

Purines and their analogues containing pyrazole or pyrazoline moiety are important structural scaffolds for the antioxidant, anti-LO and anti-thrombin activity [1], anticancer and antioxidant agents ${ }^{[2]}$. Pyrrole is an important scaffold possessing diverse number of biological activities like antimicrobial activity ${ }^{[3]}$, anticoccidial activity ${ }^{[4,}$ 5], antiinflammatory ${ }^{[6,7]}$, Antifungal ${ }^{[8]}$, and anticancer activity ${ }^{[9,10]}$. G. Narayana Swamy et al. synthesized pyrrole and pyrazole derivatives from hydrazide ${ }^{[11]}$. The chemotherapeutic uses of purines and purine analogues have prompted tremendous efforts towards their synthesis, both in the pharmaceutical industry and in academia. This article describes the preparation, characterization and anti-mitotic activity of pyrrole and pyrazole derivatives of purine. The structures of these compounds have been established by ${ }^{1} \mathrm{H}$ NMR studies, IR, Mass studies and synthesis.

\section{Materials and Methods}

Melting points were determined on Mel-temp apparatus, laboratory devices, Cambridge, MA, USA and are uncorrected. The purity of the compounds was checked by thin-layer chromatography. The infrared (IR) spectra were recorded using $\mathrm{KBr}$ pellets on Perkin-Elmer SPECTRUM 100 FT-IR spectrophotometer. ${ }^{1} \mathrm{H}$ NMR spectra were recorded at $300 \mathrm{MHz}$ on a BRUKER avance-11 FT-NMR spectrometer. The electron spray ionisation MS (ESIMS) studies were performed on triple quadrupole mass spectrometer waters Quattro Micro API.

General procedure for the preparation of pyrrole derivatives of Purine (1-5)

To a solution of the corresponding hydrazinyl purine derivatives $(1.0 \mathrm{gms})(0.0031 \mathrm{moles})$ in ethanol $(10 \mathrm{ml})$ were added acetonyl acetone $(0.0046$ moles $)$ and glacial acetic acid $(1 \mathrm{ml})$, and the reaction mass was refluxed for 4-6 hrs. After the full conversion of the starting material was detected by TLC, cooled the reaction mass to room temperature. The solid is filtered off, washed with ethanol and dried under suction.

General procedure for the preparation of pyrazole derivatives of Purine (6-10) A solution of the corresponding hydrazinyl purine derivatives $(1.0 \mathrm{gms})(0.00312 \mathrm{moles})$, $0.50 \mathrm{ml}$ of acetyl acetone in $10 \mathrm{ml}$ of water and few drops of Conc. $\mathrm{HCl}$ was stirred for 8-10 hrs at room temperature. 
After the full conversion of the starting material was detected by TLC, The solid is filtered off, washed with water followed by ethanol and dried under suction.

\section{9-(3-chloro-4-fluorophenyl)-N6-(2,5-dimethyl-1H-pyrrol-} 1-yl)-9H-purine-2,6-diamine (1)

The solid is purified in methanol to yield $0.99 \mathrm{~g}(78 \%)$ of compound (1). IR (KBr pellet), $v, \mathrm{~cm}^{-1}: 3451 \& 3316\left(-\mathrm{NH}_{2}\right)$, 3193(-NH),3080 (Ar-H), 2974(Aliphatic C-H) 1633(C=N), 1357 (C-H). ${ }^{1} \mathrm{HNMR}$ (DMSO-d $)_{6}$, $\delta$, ppm (J, Hz): 2.01 (s, $6 \mathrm{H}, 2-\mathrm{CH} 3$ ), 5.65 (s, 2H, Pyrrole $\mathrm{CH}), 6.23$ (s, 2H, $\mathrm{NH}_{2}$ ), 7.60-8.19 (m, 3H, Ar-H), 8.25 (s, 1H, CH), 10.26 (b, 1H,NH), Mass: $372.2(\mathrm{M}+1), \mathrm{mp} 298-300^{\circ} \mathrm{C}$.

\section{9-(4-bromophenyl)-N6-(2,5-dimethyl-1H-pyrrol-1-yl) 9H-purine-2,6-diamine (2)}

The solid is purified in methanol to yield $0.84 \mathrm{~g}(68 \%)$ of compound (2). IR (KBr pellet), $v, \mathrm{~cm}^{-1}: 3453 \& 3321\left(-\mathrm{NH}_{2}\right)$, 3202(-NH),3086(Ar-H), 2973(Aliphatic C-H) 1632(C=N), $1336(\mathrm{C}-\mathrm{H}) .{ }^{1} \mathrm{HNMR}\left(\mathrm{DMSO}_{\mathrm{d}}\right), \delta, \mathrm{ppm}(\mathrm{J}, \mathrm{Hz}): 2.02$ (s,6H,2-CH3), 5.66 (s,2H,Pyrrole $\mathrm{CH}), 6.22\left(\mathrm{~b}, 2 \mathrm{H}, \mathrm{NH}_{2}\right)$, 7.74-7.87 (m,4H, Ar-H), 8.25 (s,1H, CH), 10.30 (s,1H,NH), Mass: $398(\mathrm{M}+1), \mathrm{mp}>320{ }^{\circ} \mathrm{C}$.

\section{9-(4-chlorophenyl)-N6-(2,5-dimethyl-1H-pyrrol-1-yl)- 9H-purine-2,6-diamine (3)}

The solid is purified in methanol to yield $0.92 \mathrm{~g}(72 \%)$ of compound (3). IR (KBr pellet), v, $\mathrm{cm}^{-1}: 3454 \& 3324\left(-\mathrm{NH}_{2}\right)$, 3205(-NH),3088(Ar-H), 2974(Aliphatic C-H) 1632(C=N), $1338(\mathrm{C}-\mathrm{H}) .{ }^{1} \mathrm{HNMR}\left(\mathrm{DMSO}-\mathrm{d}_{6}\right), \delta, \mathrm{ppm}(\mathrm{J}, \mathrm{Hz}): 2.02$ (s,6H, 2-CH3), 5.66 (s,2H,Pyrrole $\mathrm{CH}), 6.21$ (b,2H, $\left.\mathrm{NH}_{2}\right)$, 7.60-7.93 (m,4H, Ar-H), 8.25 (s,1H, CH), 10.29 (b,1H,NH), Mass: $354(\mathrm{M}+1), \mathrm{mp}>320{ }^{\circ} \mathrm{C}$.

\section{9-(3-chlorophenyl)-N6-(2,5-dimethyl-1H-pyrrol-1-yl)- 9H-purine-2,6-diamine (4)}

The solid is purified in methanol to yield $0.95 \mathrm{~g}(74 \%)$ of compound (4). IR (KBr pellet), v, cm ${ }^{-1}: 3446 \& 3317\left(-\mathrm{NH}_{2}\right)$, 3198(-NH),3063(Ar-H), 2976(Aliphatic C-H) 1634(C=N), $1356(\mathrm{C}-\mathrm{H}) .{ }^{1} \mathrm{HNMR}\left(\mathrm{DMSO}_{\mathrm{d}}\right), \delta, \operatorname{ppm}(\mathrm{J}, \mathrm{Hz}): 2.02$ (s,6H,2-CH3), $5.66(\mathrm{~s}, 2 \mathrm{H}$, Pyrrole $\mathrm{CH}), 6.24\left(\mathrm{~s}, 2 \mathrm{H}, \mathrm{NH}_{2}\right)$, 7.45-8.05 (m,4H, Ar-H), 8.30 (s,1H,CH), 10.28 (b,1H,NH), Mass: $354.2(\mathrm{M}+1)$, mp: $319-321{ }^{\circ} \mathrm{C}$.

\section{9-(3,4-dichlorophenyl)-N6-(2,5-dimethyl-1H-pyrrol-1- yl)-9H-purine-2,6-diamine (5)}

The solid is purified in methanol to yield $0.81 \mathrm{~g}(65 \%)$ of compound (5). IR (KBr pellet), v, $\mathrm{cm}^{-1}: 3448 \& 3317\left(-\mathrm{NH}_{2}\right)$, 3193(-NH),3073(Ar-H), 2949(Aliphatic C-H) 1631(C=N), 1340(C-H). ${ }^{1} \mathrm{HNMR}$ (DMSO-d $), \delta, \quad p p m ~(J, ~ H z): 2.02$ (s,6H,2-CH3), 5.66 (s,2H, Pyrrole $\mathrm{CH}), 6.28\left(\mathrm{~s}, 2 \mathrm{H}, \mathrm{NH}_{2}\right)$, 7.81-8.30 (m,4H, Ar-H), 8.33 (s,1H, CH), 10.31 (b,1H,NH), Mass: $388.2(\mathrm{M}+1), \mathrm{mp}: 309-312^{\circ} \mathrm{C}$.

9-(3-chloro-4-fluorophenyl)-6-(3,5-dimethyl-1H-pyrazol1-yl)-9H-purin-2-amine (6)

The solid is purified in ethanol to yield $0.79 \mathrm{~g}(65 \%)$ of compound (6). IR (KBr pellet), $v, \mathrm{~cm}^{-1}$ : 3357\&3109($\left.\mathrm{NH}_{2}\right), 3082(\mathrm{Ar}-\mathrm{H}), \quad 1626(\mathrm{C}=\mathrm{N}), \quad 1354(\mathrm{C}-\mathrm{H}) . \quad{ }^{1} \mathrm{HNMR}$ (DMSO-d $), \delta, \operatorname{ppm}(\mathrm{J}, \mathrm{Hz}): 2.22\left(\mathrm{~s}, 3 \mathrm{H}, \mathrm{CH}_{3}\right), 2.52$ $\left(\mathrm{s}, 3 \mathrm{H}, \mathrm{CH}_{3}\right), 6.16(\mathrm{~s}, 1 \mathrm{H}$, Pyrazol CH$), 6.88\left(\mathrm{~s}, 2 \mathrm{H}, \mathrm{NH}_{2}\right), 8.22-$ $7.64(\mathrm{~m}, 3 \mathrm{H}, \mathrm{Ar}-\mathrm{H}), 8.49(\mathrm{~s}, 1 \mathrm{H}, \mathrm{CH})$ Mass: $358.2(\mathrm{M}+1), \mathrm{mp}$ 258-260 ${ }^{\circ} \mathrm{C}$.

9-(4-bromophenyl)-6-(3,5-dimethyl-1H-pyrazol-1-yl)-9Hpurin-2-amine (7)

The solid is purified in ethanol to yield $0.66 \mathrm{~g}(55 \%)$ of compound (7). IR (KBr pellet), $v, \mathrm{~cm}^{-1}: 3434 \& 3350\left(-\mathrm{NH}_{2}\right)$, 3064(Ar-H), 2979(Aliphatic C-H) 1626(C=N), 1355 (C-H). ${ }^{1} \mathrm{HNMR}\left(\mathrm{DMSO}-\mathrm{d}_{6}\right), \delta, \mathrm{ppm}(\mathrm{J}, \mathrm{Hz}): 2.22\left(\mathrm{~s}, 3 \mathrm{H}, \mathrm{CH}_{3}\right), 2.53$ $\left(\mathrm{s}, 3 \mathrm{H}, \mathrm{CH}_{3}\right), 6.16(\mathrm{~s}, 1 \mathrm{H}$, Pyrazol $\mathrm{CH}), 6.85\left(\mathrm{~s}, 2 \mathrm{H}, \mathrm{NH}_{2}\right)$, 7.88-7.78 (m,4H, Ar-H), $8.51(\mathrm{~s}, 1 \mathrm{H}, \mathrm{CH})$ Mass: 384.2 $(\mathrm{M}+1), \mathrm{mp} 256-259{ }^{\circ} \mathrm{C}$.

\section{9-(4-chlorophenyl)-6-(3,5-dimethyl-1H-pyrazol-1-yl)-9H- purin-2-amine (8)}

The solid is purified in ethanol to yield $0.71 \mathrm{~g}(58 \%)$ of compound (8). IR (KBr pellet), $v, \mathrm{~cm}^{-1}: 3431 \& 3350\left(-\mathrm{NH}_{2}\right)$, 3064(Ar-H), 2980(Aliphatic C-H) 1628(C=N), $1357(\mathrm{C}-\mathrm{H})$. ${ }^{1} \mathrm{HNMR}$ (DMSO-d 6 ), $\delta$, ppm (J, Hz): $2.23\left(\mathrm{~s}, 3 \mathrm{H}, \mathrm{CH}_{3}\right), 2.56$ $\left(\mathrm{s}, 3 \mathrm{H}, \mathrm{CH}_{3}\right), 6.18(\mathrm{~s}, 1 \mathrm{H}$, Pyrazol $\mathrm{CH}), 6.94\left(\mathrm{~b}, 2 \mathrm{H}, \mathrm{NH}_{2}\right)$, 7.94-7.67 (m,3H,ArH), 8.70 (s,1H,CH) Mass: 340.2(M+1), mp 220-222 ${ }^{\circ} \mathrm{C}$.

\section{9-(3-chlorophenyl)-6-(3,5-dimethyl-1H-pyrazol-1-yl)-9H-} purin-2-amine (9)

The solid is purified in ethanol to yield $0.75 \mathrm{~g}(61 \%)$ of compound (9). IR (KBr pellet), $v, \mathrm{~cm}^{-1}: 3454 \& 3367\left(-\mathrm{NH}_{2}\right)$, 3082(Ar-H), 3040(Aliphatic C-H) 1619(C=N), $1357(\mathrm{C}-\mathrm{H})$. ${ }^{1} \mathrm{HNMR}\left(\mathrm{DMSO}-\mathrm{d}_{6}\right), \delta$, ppm $(\mathrm{J}, \mathrm{Hz}): 2.23\left(\mathrm{~s}, 3 \mathrm{H}, \mathrm{CH}_{3}\right), 2.56$ $\left(\mathrm{s}, 3 \mathrm{H}, \mathrm{CH}_{3}\right), 6.18(\mathrm{~s}, 1 \mathrm{H}$, Pyrazol $\mathrm{CH}), 6.99\left(\mathrm{~b}, 2 \mathrm{H}, \mathrm{NH}_{2}\right)$, 7.94-7.67 (m,3H,ArH), 8.73 (s,1H,CH) Mass:340.2 (M+1), m.p $148-150{ }^{\circ} \mathrm{C}$.

9-(3,4-dichlorophenyl)-6-(3,5-dimethyl-1H-pyrazol-1-yl)9H-purin-2-amine (10)

The solid is purified in ethanol to yield $0.71 \mathrm{~g} \mathrm{(59 \% )} \mathrm{of}$ compound (10). IR (KBr pellet), v, $\mathrm{cm}^{-1}$ : 3478\&3369($\left.\mathrm{NH}_{2}\right), 3079($ Ar-H), 2986(Aliphatic C-H) 1631(C=N), 1346 (C-H). ${ }^{1} \mathrm{HNMR}$ (DMSO-d $), \delta, \operatorname{ppm}(\mathrm{J}, \mathrm{Hz}): 2.27$ (s,3H, $\left.\mathrm{CH}_{3}\right), 2.60\left(\mathrm{~s}, 3 \mathrm{H}, \mathrm{CH}_{3}\right), 6.22(\mathrm{~s}, 1 \mathrm{H}$, Pyrazol $\mathrm{CH}), 7.05$ (b,2H, $\left.\mathrm{NH}_{2}\right), 8.30-7.91$ (m,3H,ArH), 9.04 (s,1H,CH) Mass: $374.1(\mathrm{M}+1)$, m.p $266-268{ }^{\circ} \mathrm{C}$.

\section{Anti-mitotic activity \\ Methodology of Docking study}

The structure of gastrotropin of homo sapiens was obtained from PDB database and given in figure 1. After the unnecessary chains and hetero atoms were removed using SPDBV software, hydrogens were added to the protein and used for active site identification.

Active site of gastrotropin (PDB ID:1O1U) was identified using CASTp server and given in figure 2. A new program, CASTp, for automatically locating and measuring protein pockets and cavities, is based on precise computational geometry methods, including alpha shape and discrete flow theory. CASTp identifies and measures pockets and pocket mouth openings, as well as cavities. The program specifies the atoms lining pockets, pocket openings, and buried cavities; the volume and area of pockets and cavities; and the area and circumference of mouth openings. 


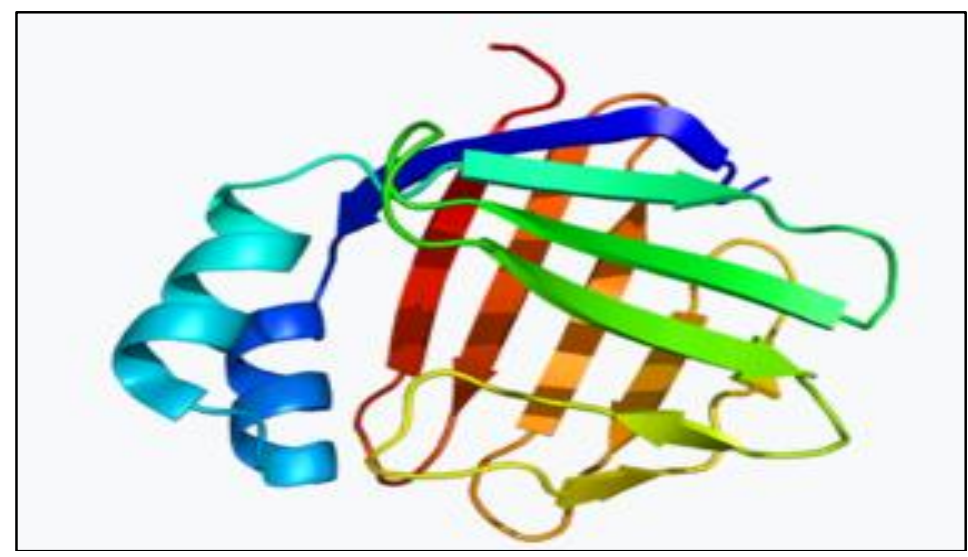

Fig 1: Structure of gastrotropin

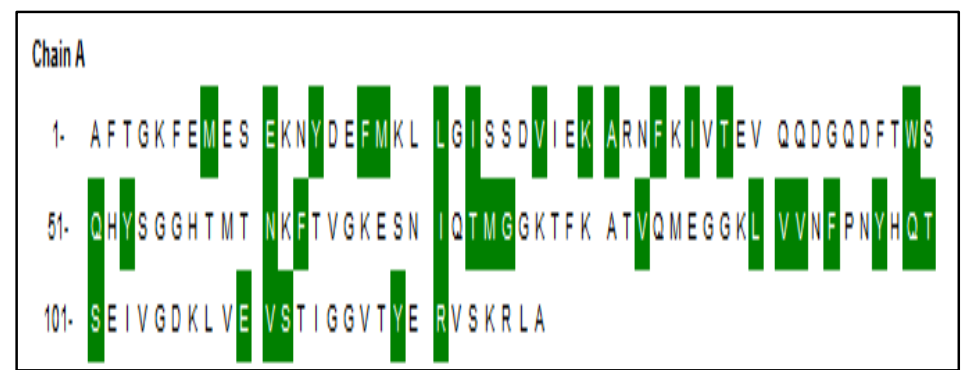

Fig 2: Active site of gastrotropin

Docking was carried out using GOLD (Genetic Optimization of Ligand Docking) software which is based on genetic algorithm (GA). The compounds are docked to the active site of the gastrotropin. The interaction of these compounds with the active site residues are thoroughly studied using molecular mechanics calculations. After docking, the individual binding poses of each ligand were observed and their interactions with the protein were studied. The best and most energetically favourable conformation of each ligand was selected.

\section{Gold Score fitness function}

Gold Score performs a force field based scoring function and is made up of four components. The external vdw score is multiplied by a factor of 1.375 when the total fitness score is computed. This is an empirical correction to encourage protein-ligand hydrophobic contact. The fitness function has been optimized for the prediction of ligand binding positions.

Gold Score $=S($ hb_ext $)+S\left(v d w \_e x t\right)+S\left(h b \_i n t\right)+S$ (vdw_int)

Where $\mathrm{S}$ (hb_ext) is the protein-ligand hydrogen bond score $\mathrm{S}$ (vdw_ext) is the protein-ligand van der Waals score $\mathrm{S}$ (hb_int) is the score from intramolecular hydrogen bond in the ligand

$\mathrm{S}$ (vdw_int) is the score from intramolecular strain in the ligand.

\section{Results and Discussion}

The synthetic pathway followed for the synthesis of purine derivatives is presented in Scheme-1. Aryl substituted derivatives were synthesized by reaction of different substituted anilines with 4,6-dichloropyrimidine-2,5diamine Hydro chloride in refluxing n-Butanol for 3-10 hrs. They were purified by using iso propyl alcohol as a solvent.
6-Chloro Purinyl derivatives were synthesized by reaction of aryl substituted pyrimidines with triethyl ortho formate in presence of Conc.Hcl at room temperature for 8-12 hrs. They were purified by using methanol as a solvent.

Hydrazinyl substituted purine derivatives were synthesized by the reaction of 6-chloro purines with hydrazine hydrate and tri ethyl amine in presence of refluxing ethanol for 2-4 hrs.

Pyrrole derivatives of purine (1-5) were synthesized by the reaction of corresponding hydrazinyl purine derivatives with acetonyl acetone in ethanol and catalytic amount of glacial acetic acid. The IR spectra of 9-(3-chloro-4-fluorophenyl)$\mathrm{N}^{6}$-(2,5-dimethyl-1H-pyrrol-1-yl)-9H-purine-2,6-diamine

(1) exhibited intense bands at $3193 \mathrm{~cm}^{-1}, 2974 \mathrm{~cm}^{-1}, 1633$ $\mathrm{cm}^{-1}$ confirming the presence of $-\mathrm{NH}$ group , aliphatic $\mathrm{C}-\mathrm{H}$ and $-\mathrm{C}=\mathrm{N}$ group respectively. ${ }^{1} \mathrm{H}$ NMR showed one singlet at $\delta 2.01(6 \mathrm{H}, 2-\mathrm{CH} 3)$, another singlet at $\delta 5.65(2 \mathrm{H}$, pyrrole- $\mathrm{CH})$ and one broad signal at $\delta 10.23(1 \mathrm{H}, \mathrm{NH})$, confirming the structure of pyrrole derivative. Similarly, remaining pyrrole derivatives 4-5 were synthesized from their corresponding hydrazinyl purine derivatives in ethanol and catalytic amount of acetic acid.

Pyrazole derivatives of purine (6-10) were synthesized by the reaction of corresponding hydrazinyl purine derivatives with acetyl acetone in water and catalytic amount of hydrochloric acid. The IR spectra of 9-(3-chloro-4fluorophenyl)-6-(3,5-dimethyl-1H-pyrazol-1-yl)-9H-purin2-amine (6) exhibited intense bands at $3082 \mathrm{~cm}^{-1}, 1626 \mathrm{~cm}^{-1}$, $1354 \mathrm{~cm}^{-1}$ confirming the presence of $-\mathrm{Ar}-\mathrm{H}, \mathrm{C}=\mathrm{N}$ group and $-\mathrm{C}-\mathrm{H}$ group respectively. ${ }^{1} \mathrm{H}$ NMR showed one singlet at $\delta 2.22(3 \mathrm{H},-\mathrm{CH} 3)$, singlet at $\delta 2.52(3 \mathrm{H},-\mathrm{CH} 3)$, another singlet at $\delta 6.16(1 \mathrm{H}$, pyrazole- $\mathrm{CH})$, confirming the structure of pyrazole derivative. Similarly, remaining pyrazole derivatives 7-10 were synthesized from their corresponding hydrazinyl purine derivatives in water and catalytic amount of hydrochloric acid. 


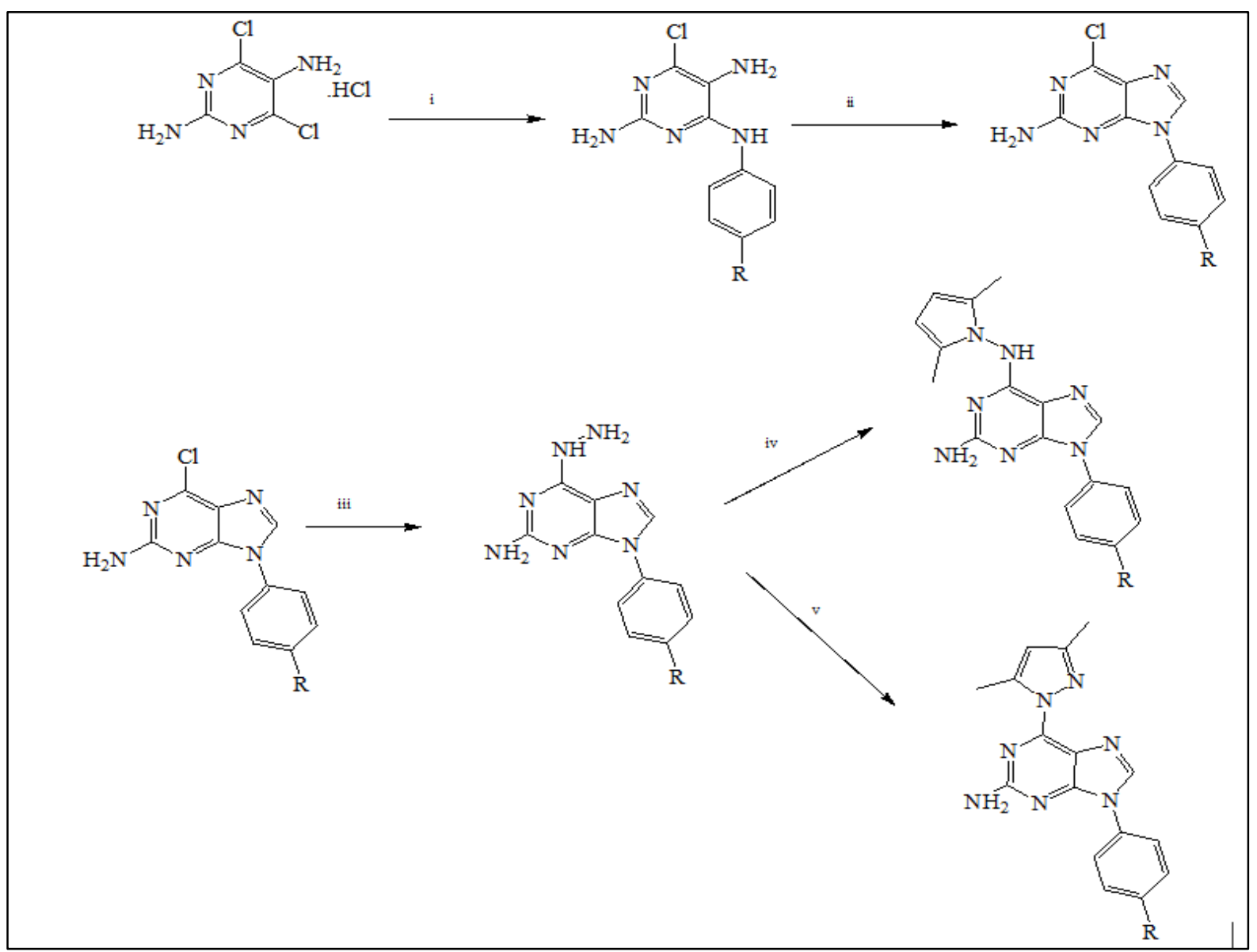

Scheme 1:- Reagents and conditions: - i) Different substituted anilines/n-Butanol, Reflux (where R defined in table-1) ii) Triethyl ortho formate/Conc.HCl, RT iii)
Hydrazine hydrate, Tri ethyl amine /Ethanol, Reflux iv) Acetonyl acetone/cat. Acetic acid/ Ethanol, Reflux v) Acetyl acetone /cat. Conc. $\mathrm{HCl} /$ Water/ RT.

Table 1: Physical properties of synthesized compounds

\begin{tabular}{|c|c|c|c|}
\hline Compound. No & $\mathbf{R}$ & Melting point $\left({ }^{\circ} \mathbf{C}\right)$ & Yield (mol \%) \\
\hline 1 & $3-\mathrm{Cl}, 4-\mathrm{F}$ & $298-300$ & 78 \\
\hline 2 & $4-\mathrm{Br}$ & $>320^{\circ} \mathrm{C}$ & 68 \\
\hline 3 & $4-\mathrm{Cl}$ & $>320^{\circ} \mathrm{C}$ & 72 \\
\hline 4 & $3-\mathrm{Cl}$ & $319-312$ & 65 \\
\hline 5 & $3,4-\mathrm{di} C h l o r o$ & $309-312$ & 65 \\
\hline 6 & $3-\mathrm{Cl}, 4-\mathrm{F}$ & $258-260$ & 55 \\
\hline 7 & $4-\mathrm{Br}$ & $256-259$ & 58 \\
\hline 8 & $4-\mathrm{Cl}$ & $220-222$ & 61 \\
\hline 10 & $3-\mathrm{Cl}$ & $148-150$ & 59 \\
\hline
\end{tabular}

\section{Anti-mitotic activity \\ Docking study}

All the Inhibitors can bind to the gastrotropin and inhibit the activity of the protein. In this study we are interested to test the role of hydrogen bonding, in binding of gastrotropin to Inhibitors (synthesized compounds). The interactions of the Inhibitors with the receptor in modeled complexes are investigated, and we shall compare the inhibition ability of gastrotropin by Inhibitors.

Docking of Inhibitors with the active site of gastrotropin To understand the interaction between gastrotropin and Inhibitors, the Inhibitor - gastrotropin complex was generated using GOLD 5.2, which is based on Rigid Body Shape-Fitting and the binding 3D conformation complex of the best docked Inhibitors. This figure shows that Inhibitors located in the center of the active site, and is stabilized by hydrogen bonding. Hydrogen bonds play an important role for structure and function of biological molecules, especially for enzyme catalysis. The bond distances $(\AA)$ and bond angles $(\AA)$ of hydrogen bonds present in the Inhibitors gastrotropin complexes are listed in Tab.2. The binding 3D conformations of all synthesized compounds with gastrotropin molecule having good binding affinity were saved and given below. 


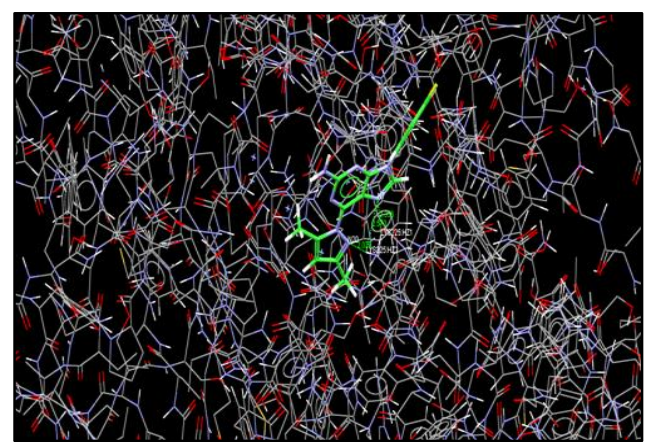

Compound No. 1

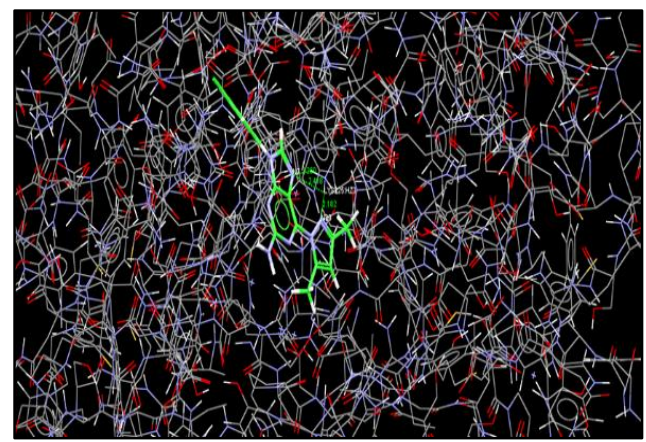

Compound No. 3

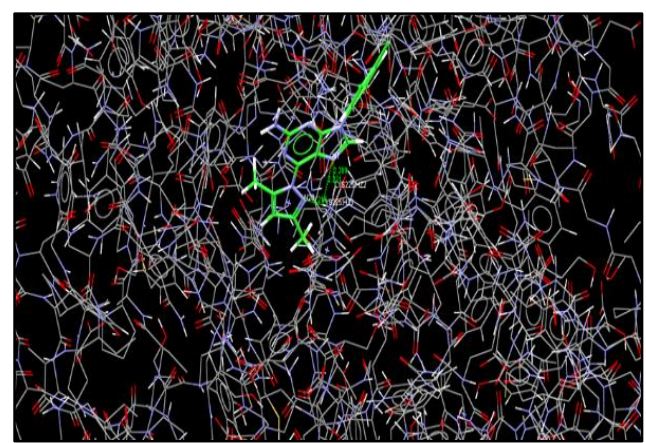

Compound No. 5

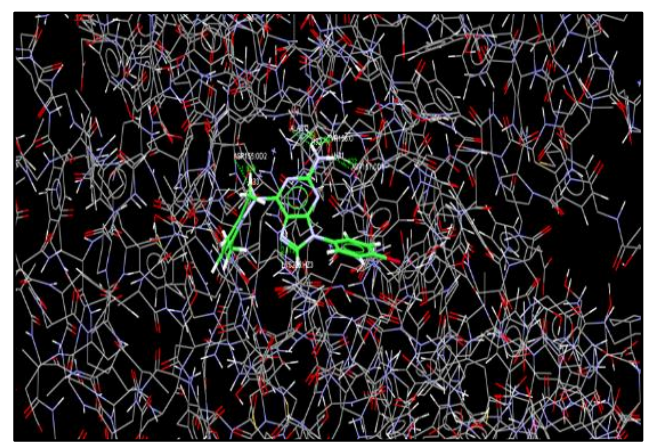

Compound No. 7

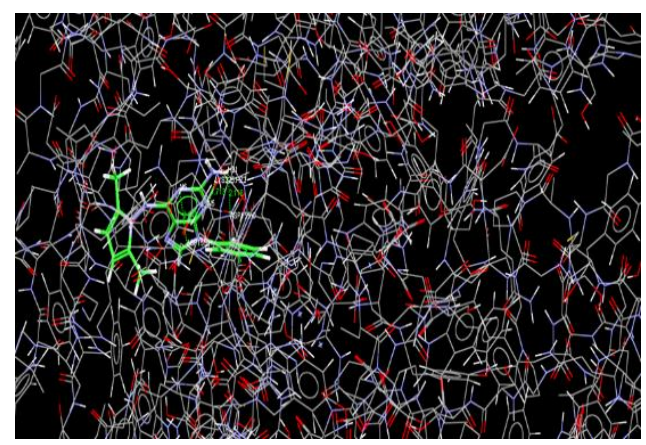

Compound No. 9

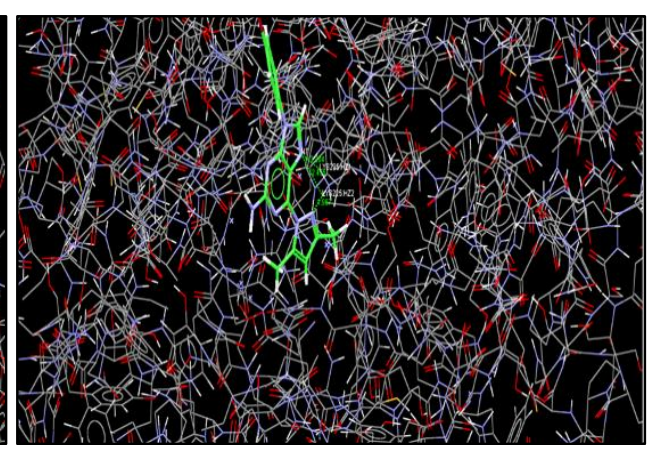

Compound No. 2

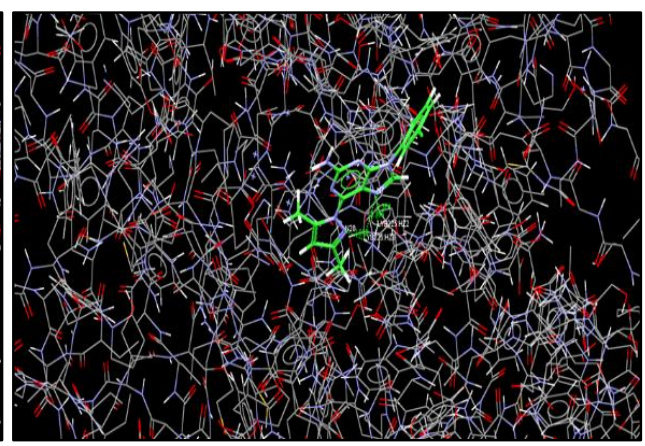

Compound No. 4

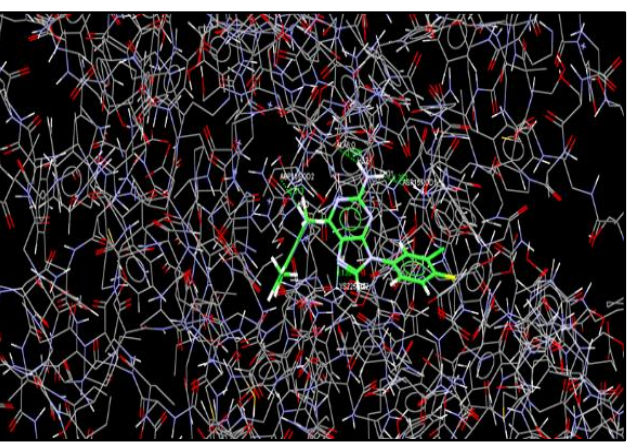

Compound No. 6

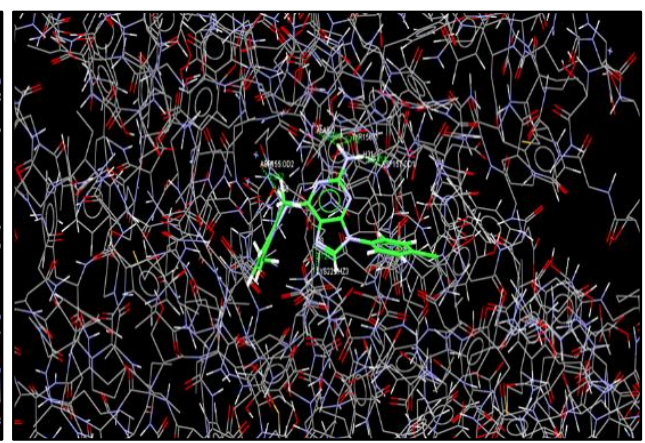

Compound No. 8

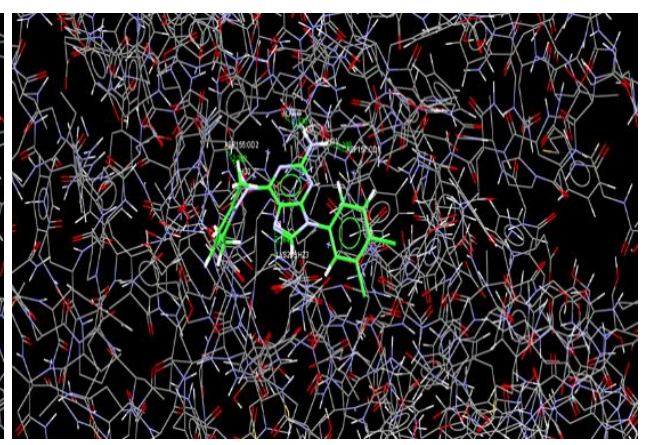

Compound No. 10 


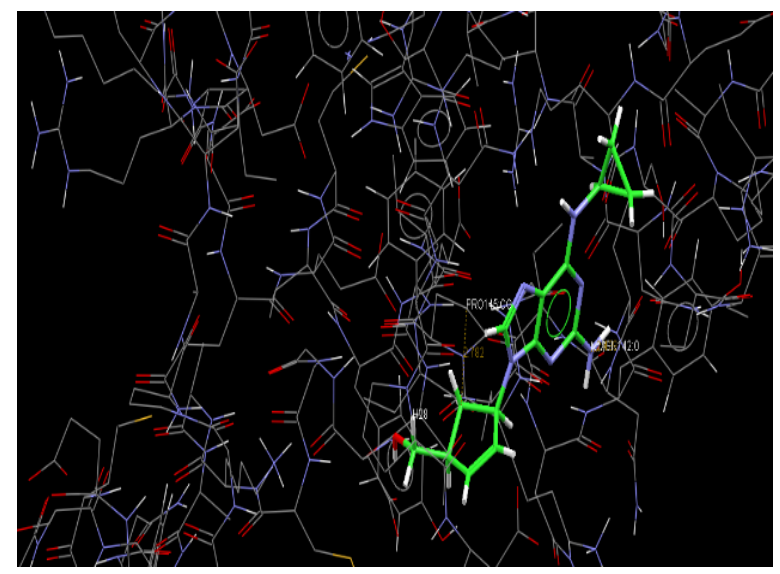

Abacavir (Std.)

Fig 3: Shows binding of Gastrotropin molecule to synthesized compounds having good affinity

Table 2: The fitness of the top-ranked individual for each ligand docked in GOLD. Format

\begin{tabular}{|c|c|c|c|c|c|}
\hline Compound No. & Fitness & S(hb_ext) & S(vdw_ext) & S(hb_int) & S(int) \\
\hline 1 & 40.27 & 2.57 & $27 . \overline{86}$ & 0.00 & -0.61 \\
\hline 2 & 40.15 & 2.52 & 27.94 & 0.00 & -0.78 \\
\hline 3 & 39.39 & 2.65 & 27.40 & 0.00 & -0.93 \\
\hline 4 & 37.58 & 2.24 & 26.67 & 0.00 & -1.34 \\
\hline 5 & 39.60 & 2.56 & 27.58 & 0.00 & -0.87 \\
\hline 6 & 28.33 & 7.72 & 19.11 & 0.00 & -5.66 \\
\hline 7 & 29.64 & 7.35 & 19.61 & 0.00 & -4.68 \\
\hline 8 & 29.28 & 7.41 & 19.13 & 0.00 & -4.43 \\
\hline 9 & 29.70 & 1.43 & 23.71 & 0.00 & -4.33 \\
\hline 10 & 28.65 & 7.70 & 18.64 & 0.00 & -4.68 \\
\hline Abacavir & 43.44 & 6.00 & 30.52 & 0.00 & -4.52 \\
\hline
\end{tabular}

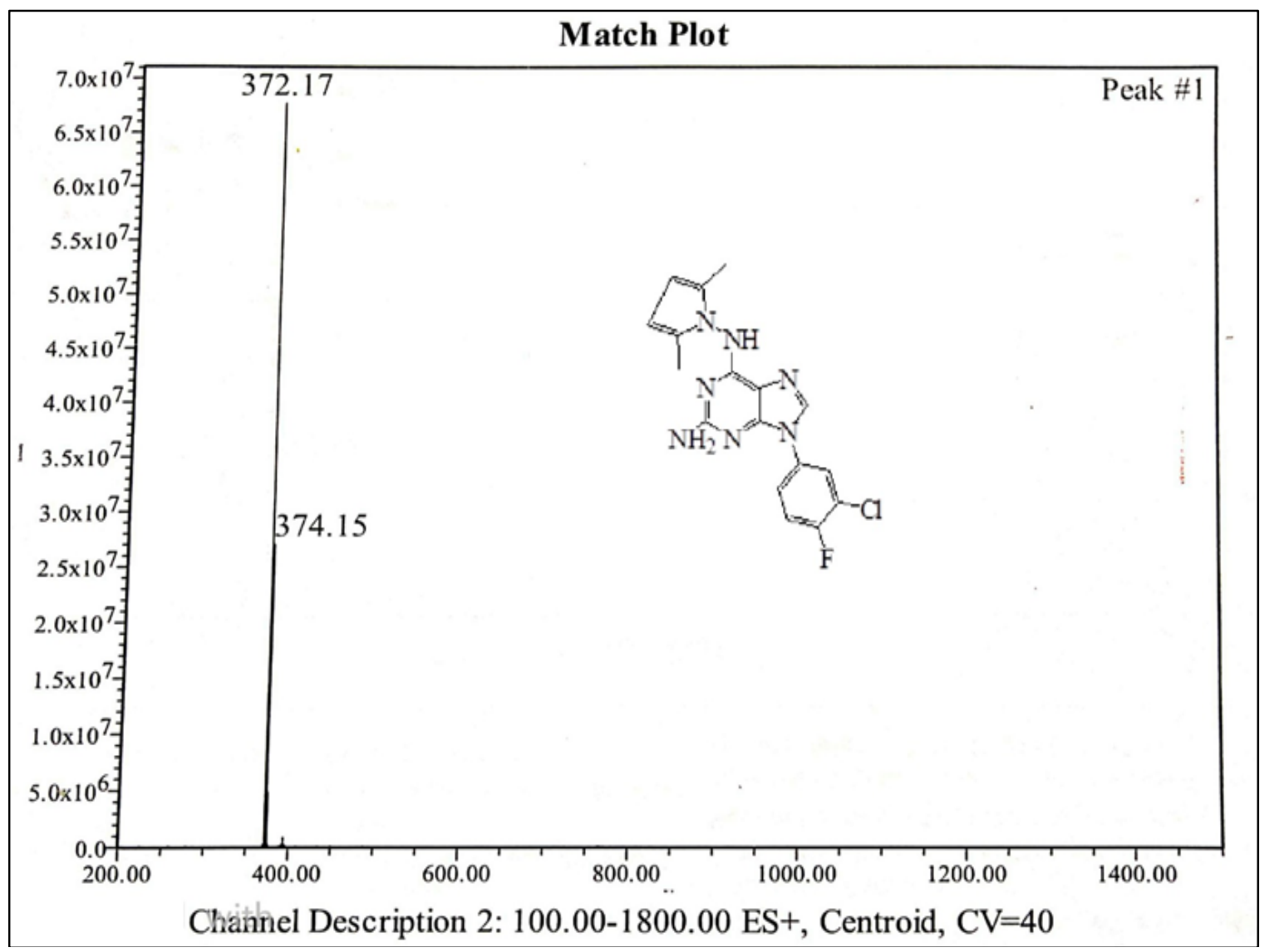

Fig 4: Mass spectra of 9-(3-chloro-4-fluorophenyl)-N6-(2,5-dimethyl-1H-pyrrol-1-yl)-9H-purine-2,6-diamine 


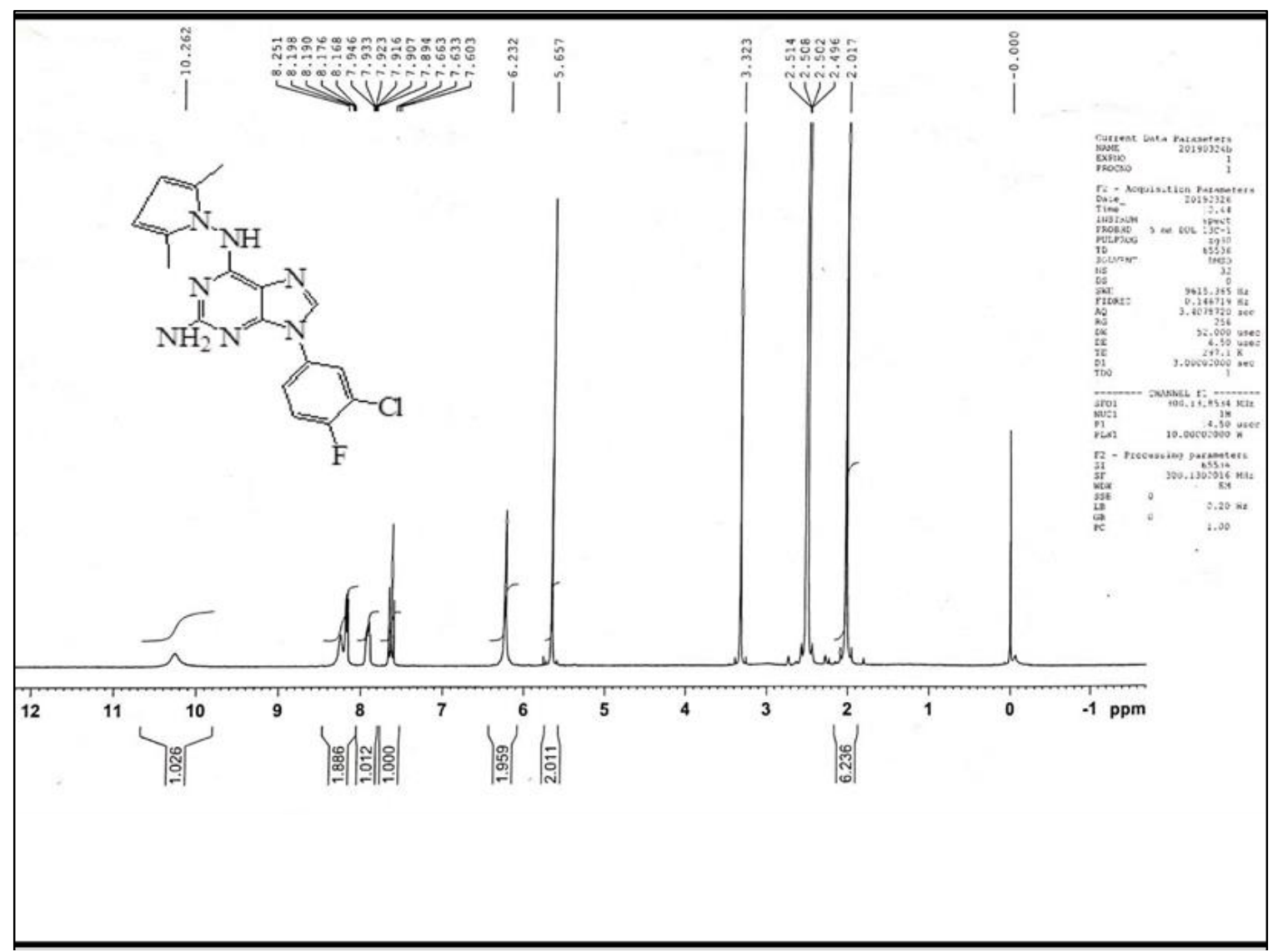

Fig 5:1H NMR spectra of 9-(3-chloro-4-fluorophenyl)-N6-(2,5-dimethyl-1H-pyrrol-1-yl)-9H-purine-2,6-diamine

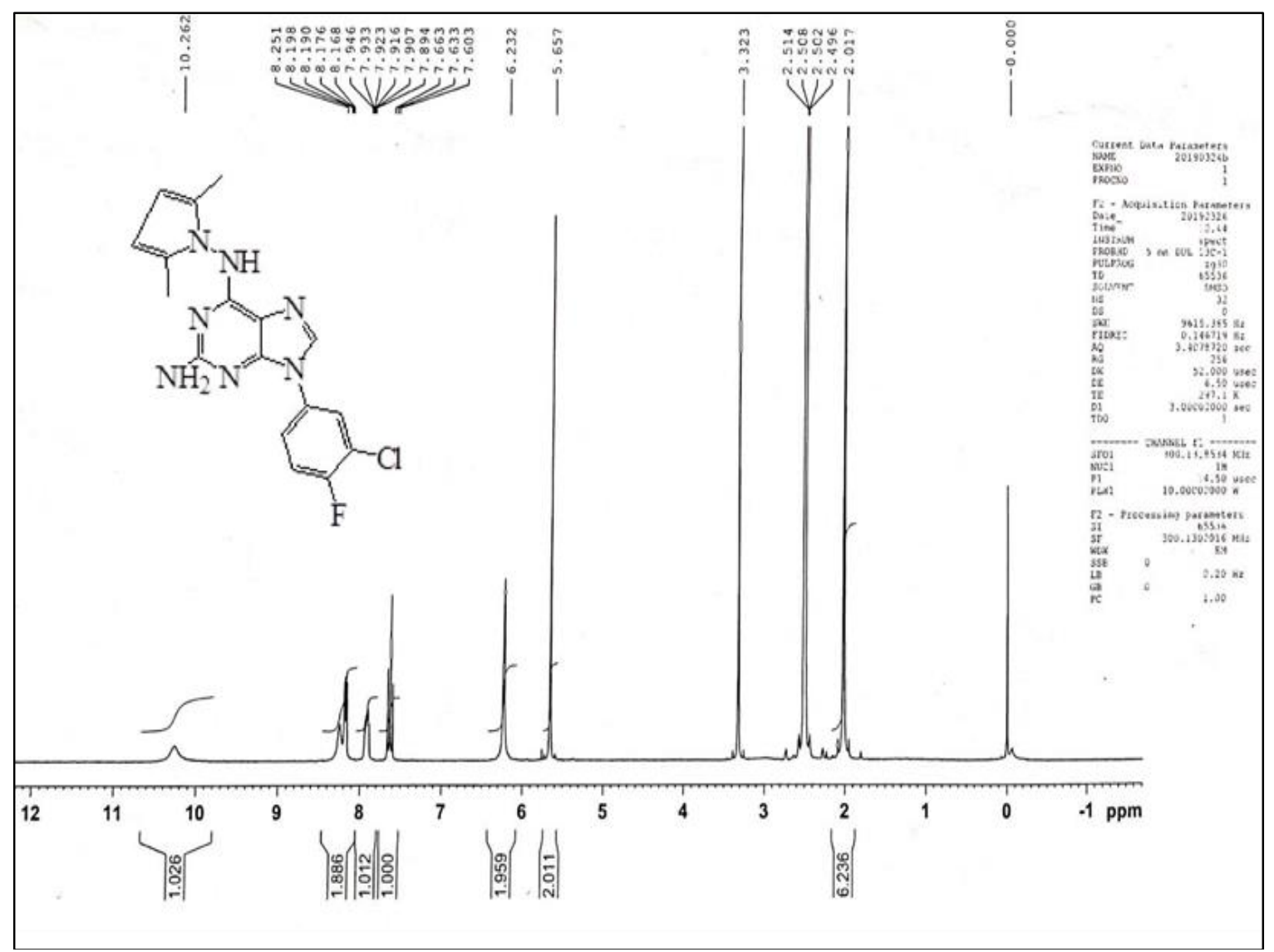

Fig 5: IR spectra of 9-(3-chloro-4-fluorophenyl)-N6-(2,5-dimethyl-1H-pyrrol-1-yl)-9H-purine-2,6-diamine 


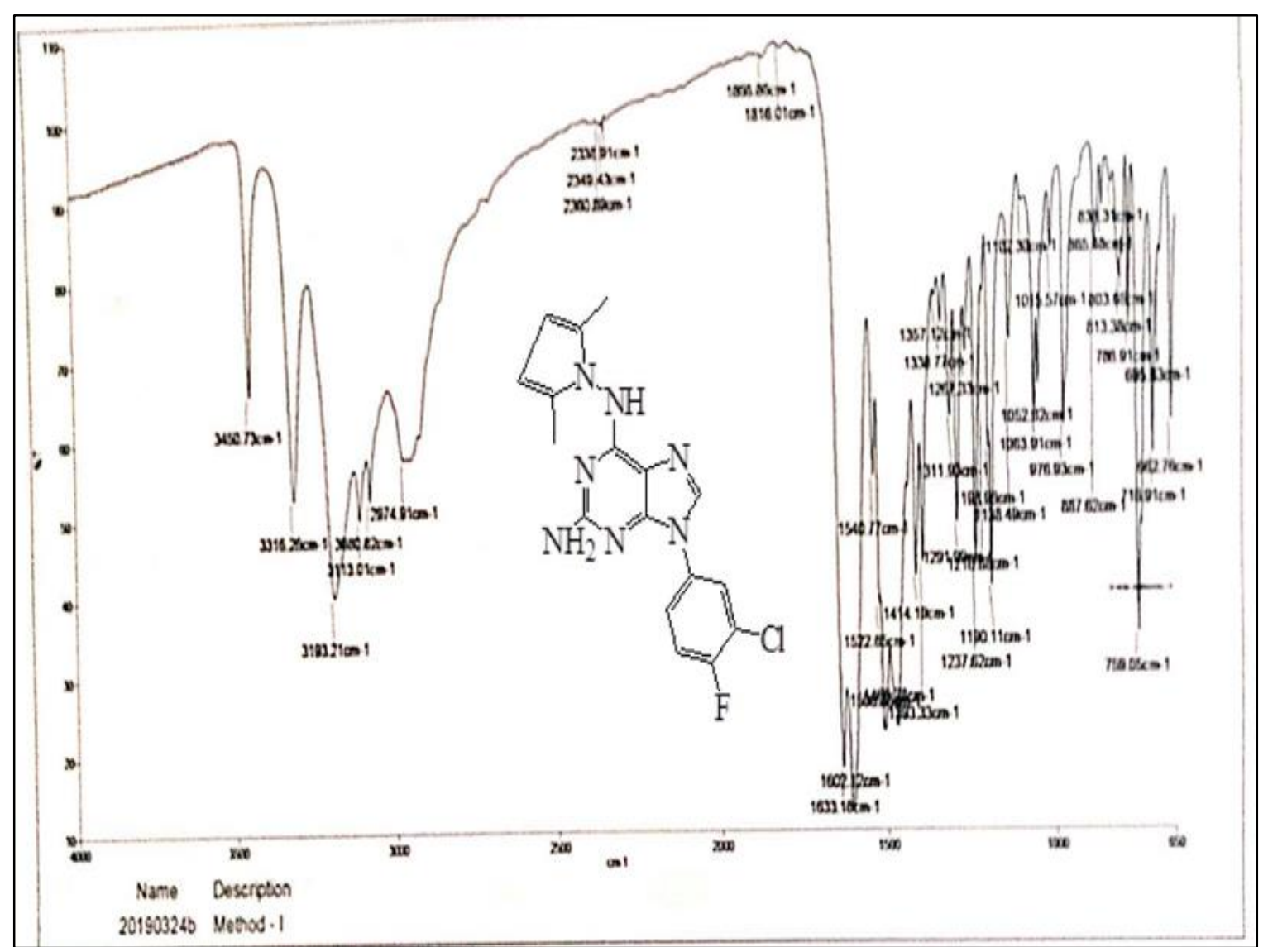

Fig 6: Mass spectra of 9-(4-bromophenyl)-N6-(2,5-dimethyl-1H-pyrrol-1-yl)-9H-purine-2,6-diamine

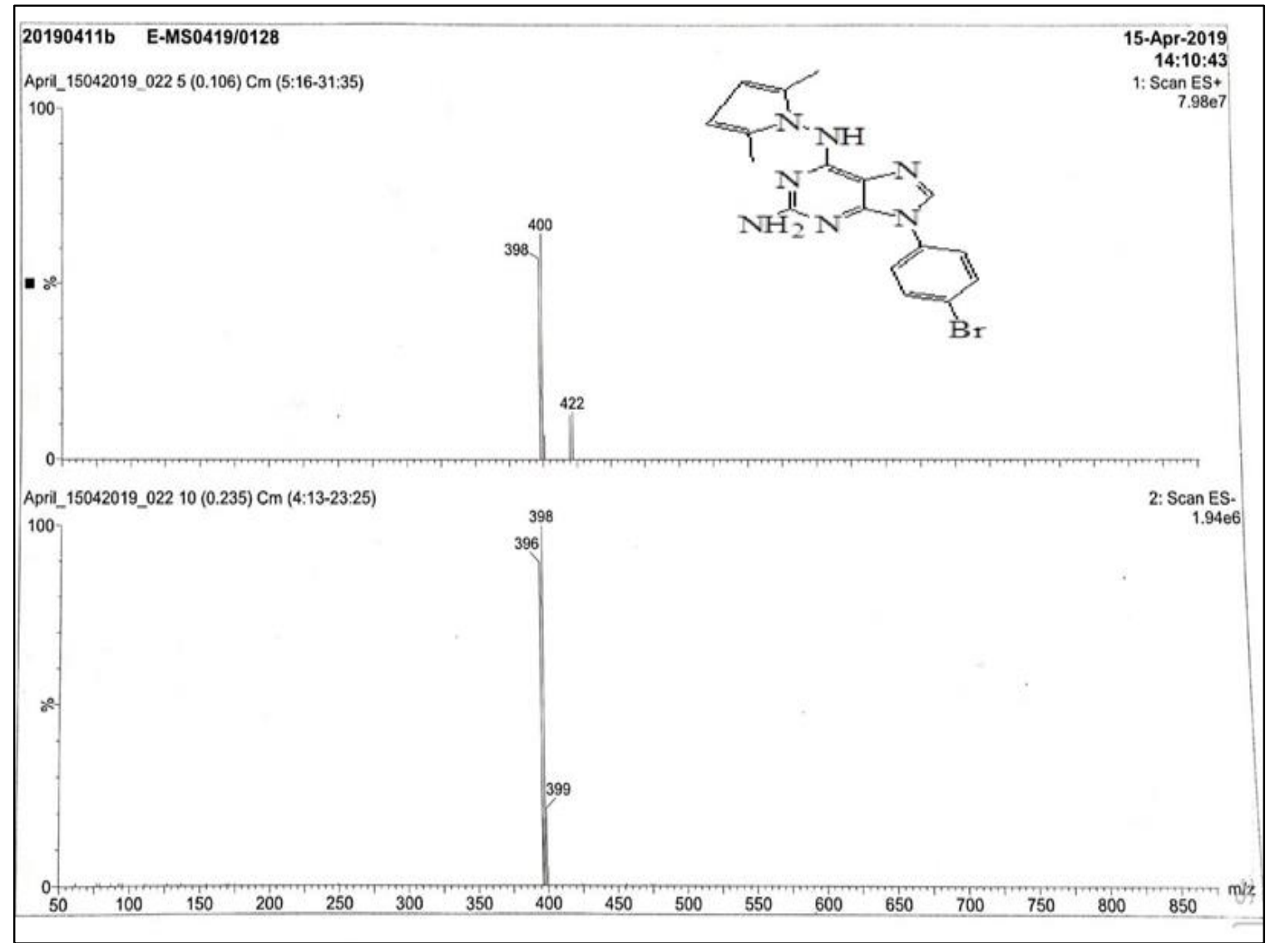

Fig 7: 1H NMR spectra of 9-(4-bromophenyl)-N6-(2,5-dimethyl-1H-pyrrol-1-yl)-9H-purine-2,6-diamine 


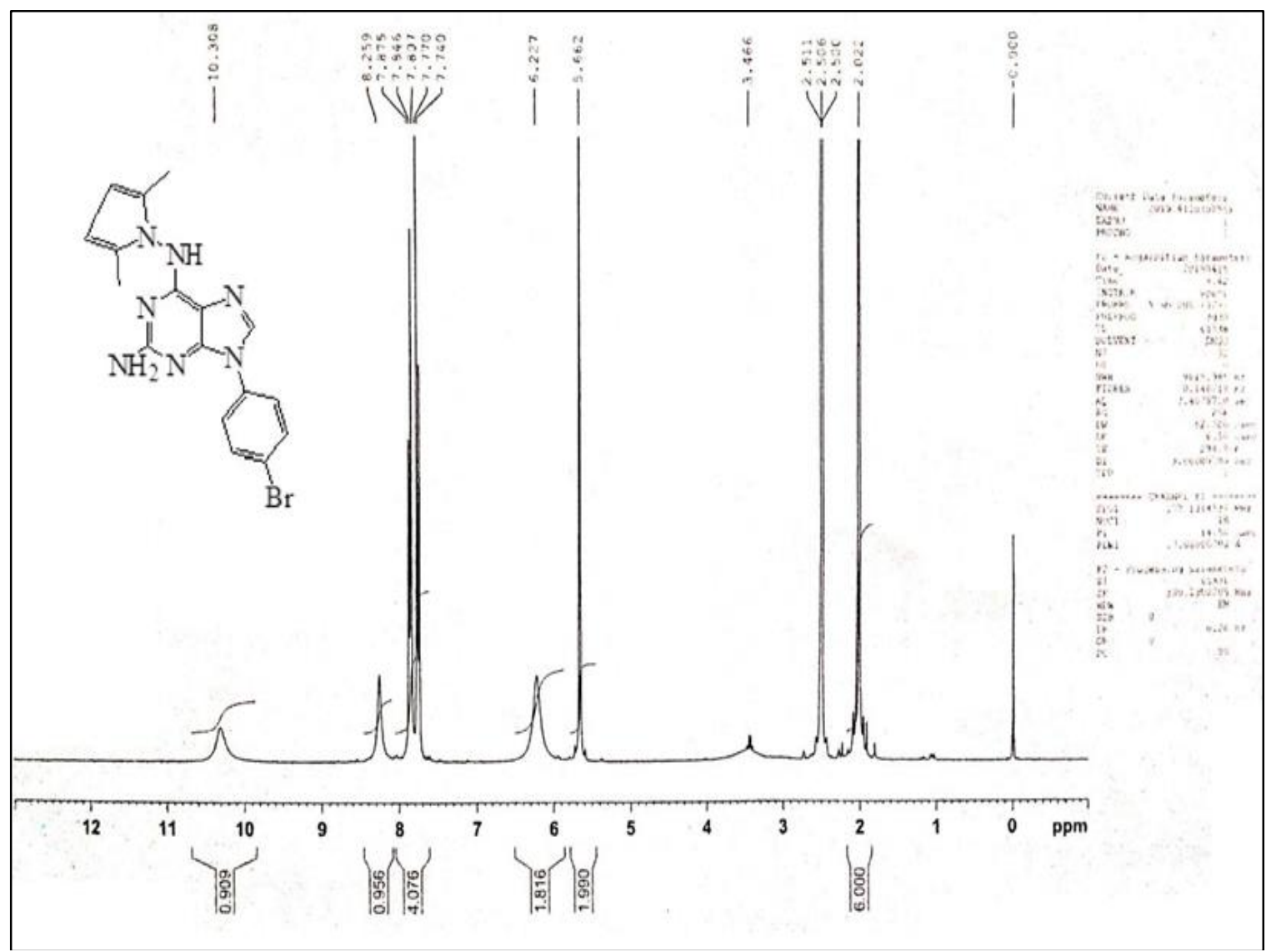

Fig 8: IR spectra of 9-(4-bromophenyl)-N6-(2,5-dimethyl-1H-pyrrol-1-yl)-9H-purine-2,6-diamine

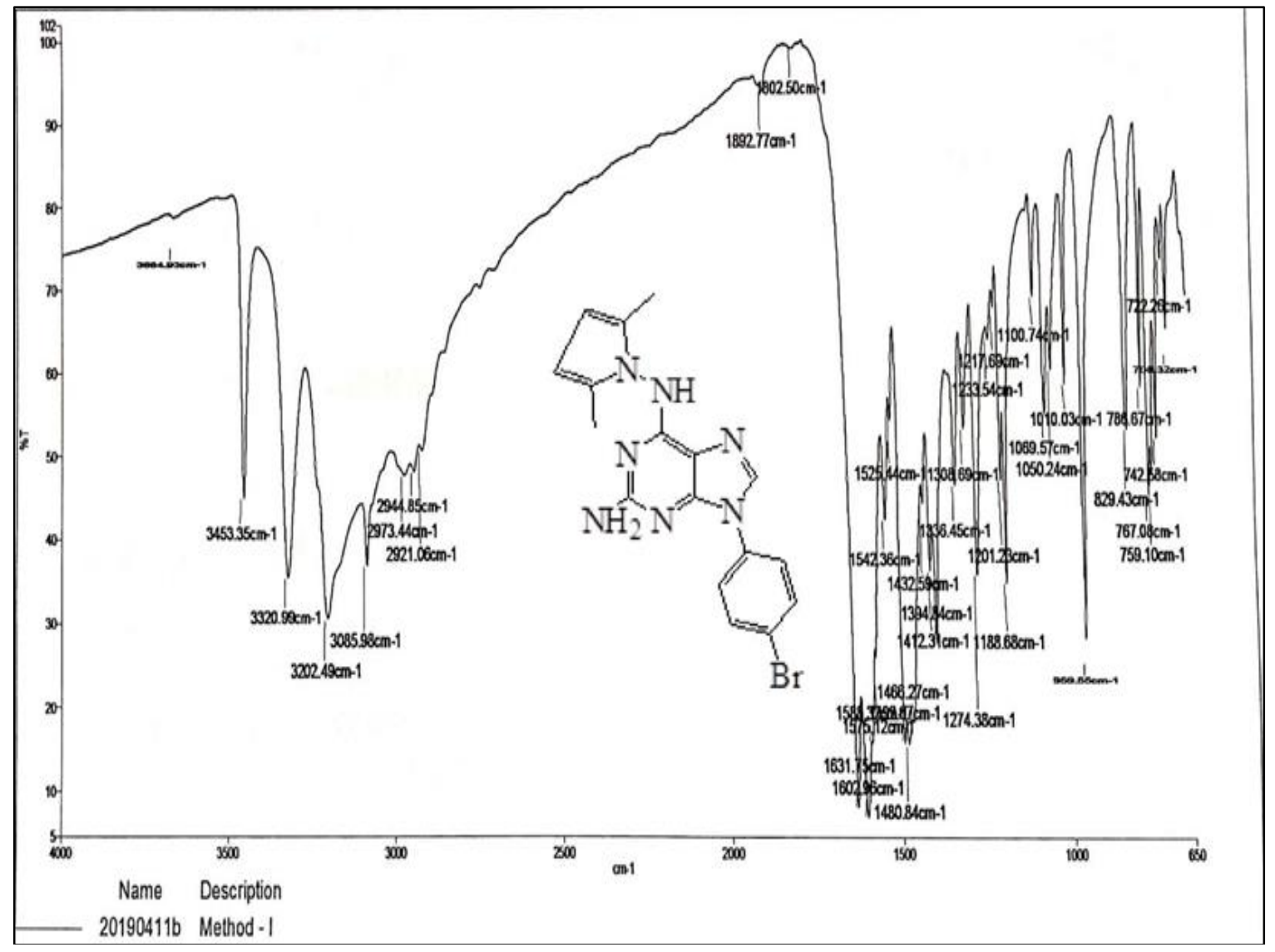

Fig 9: Mass spectra of 9-(4-chlorophenyl)-N6-(2,5-dimethyl-1H-pyrrol-1-yl)-9H-purine-2,6-diamine 


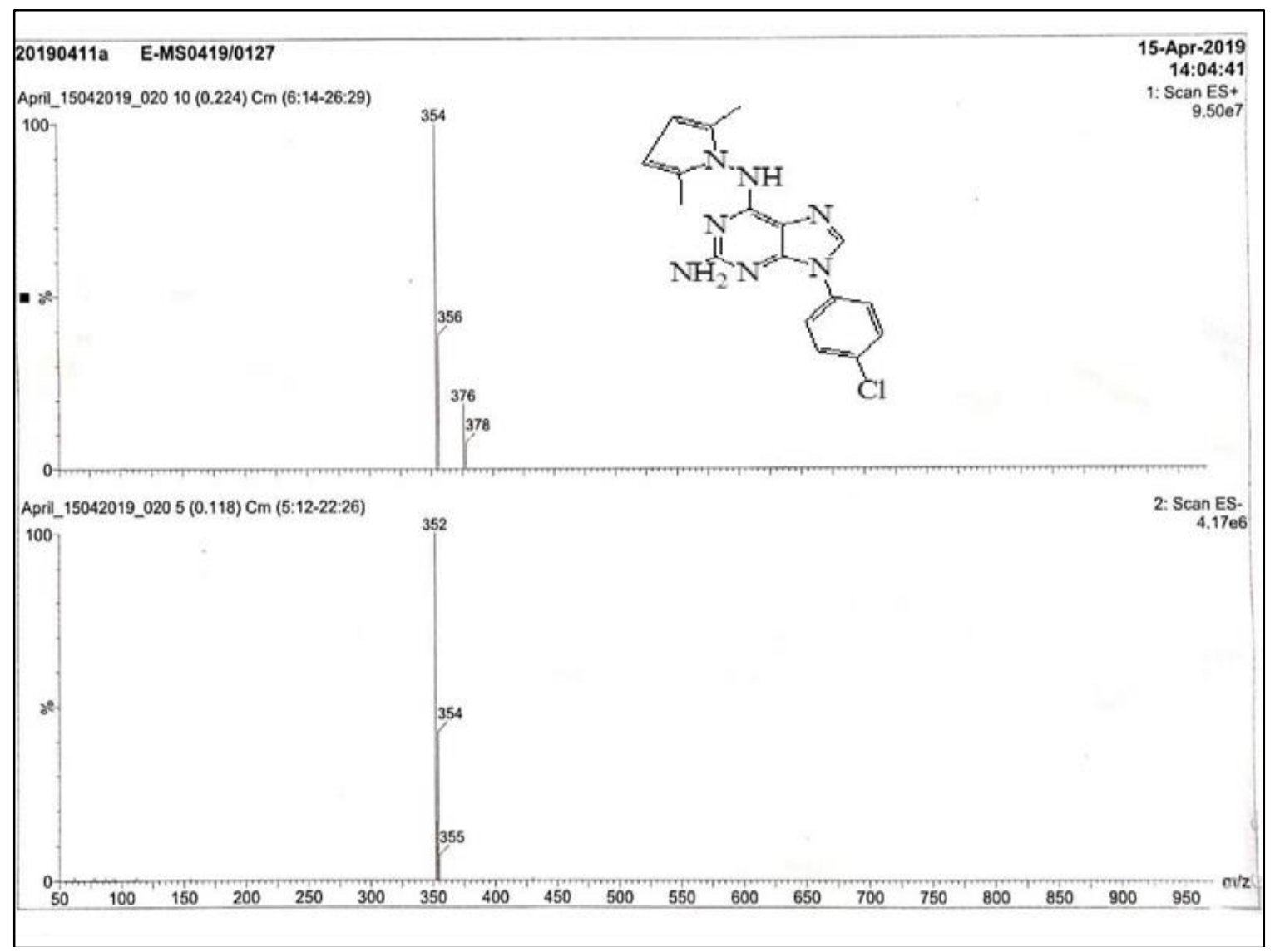

Fig 10:1H NMR spectra of 9-(4-chlorophenyl)-N6-(2,5-dimethyl-1H-pyrrol-1-yl)-9H-purine-2,6-diamine

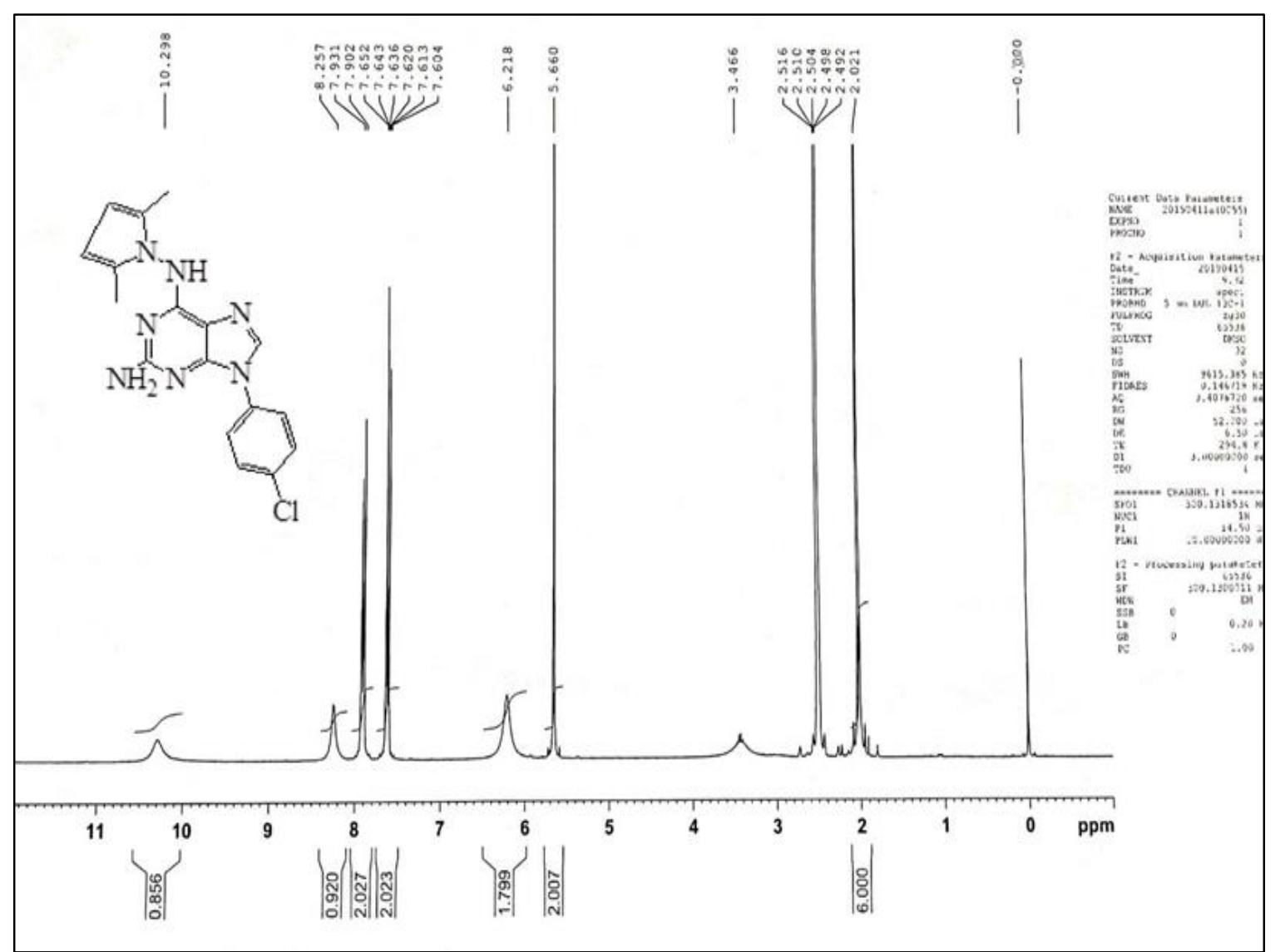

Fig 11: IR spectra of 9-(4-chlorophenyl)-N6-(2,5-dimethyl-1H-pyrrol-1-yl)-9H-purine-2,6-diamine 


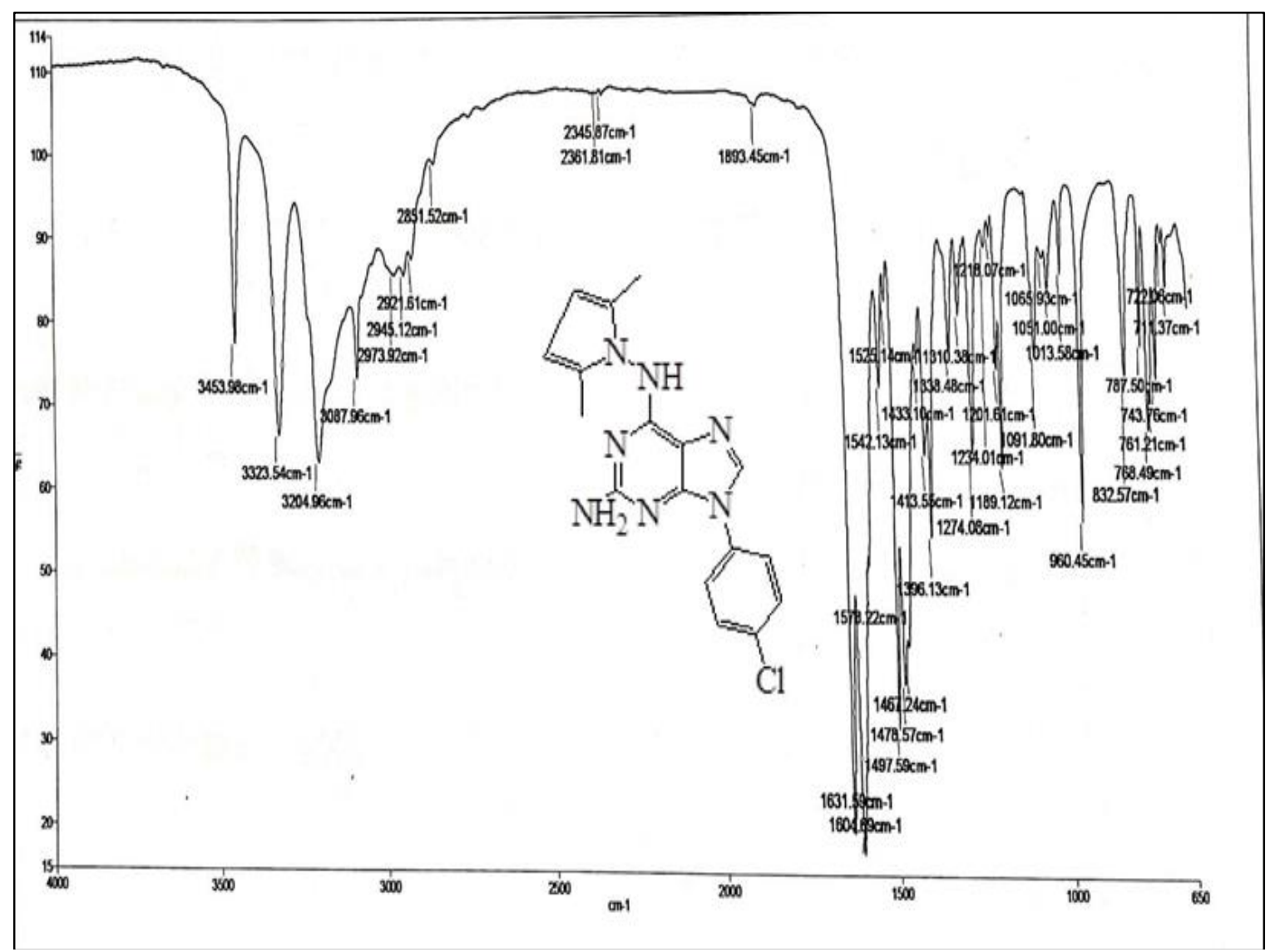

Fig 12: Mass spectra of 9-(3-chlorophenyl)-N6-(2,5-dimethyl-1H-pyrrol-1-yl)-9H-purine-2,6-diamine

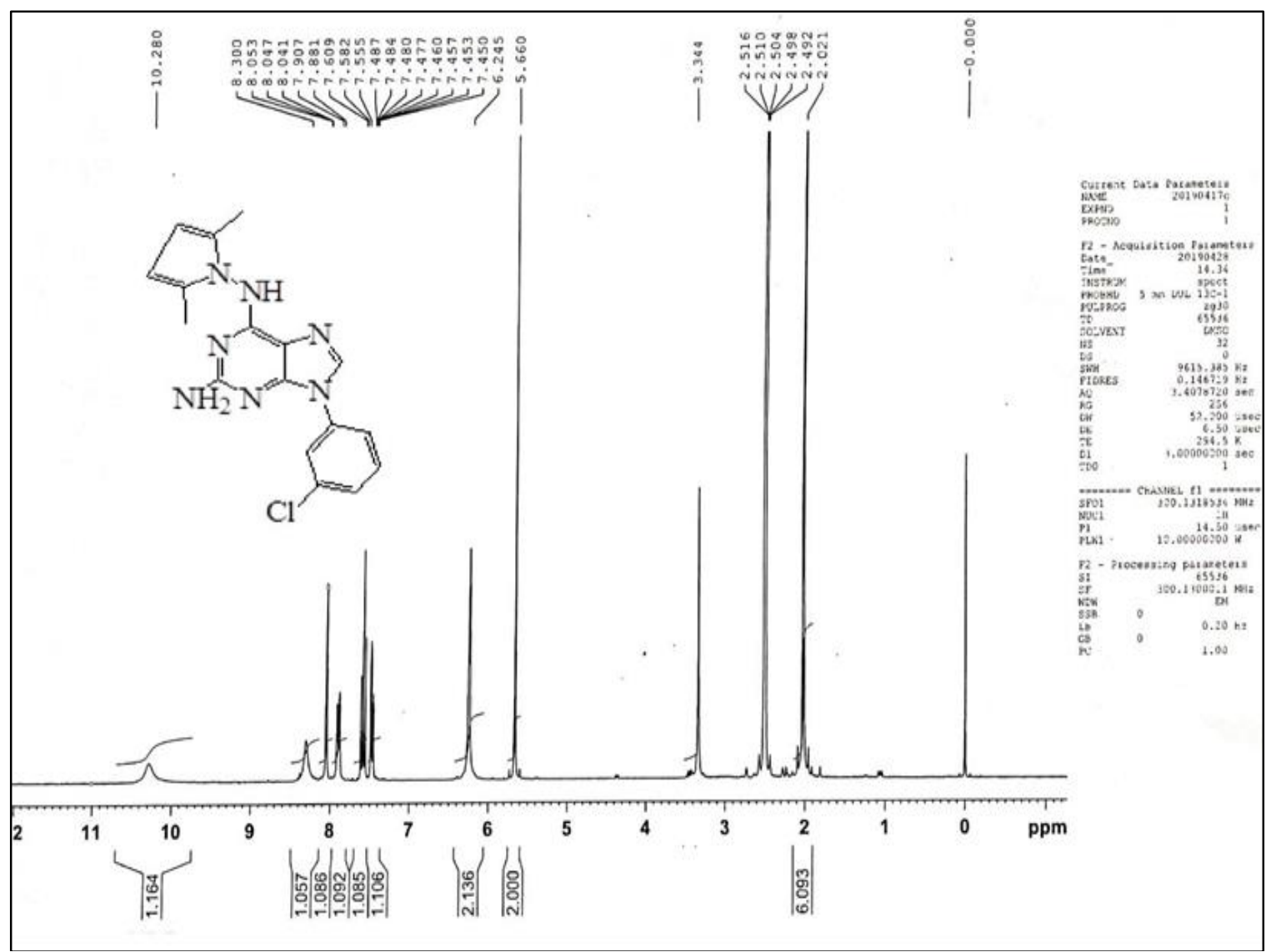

Fig 13: H NMR spectra of 9-(3-chlorophenyl)-N6-(2,5-dimethyl-1H-pyrrol-1-yl)-9H-purine-2,6-diamine 


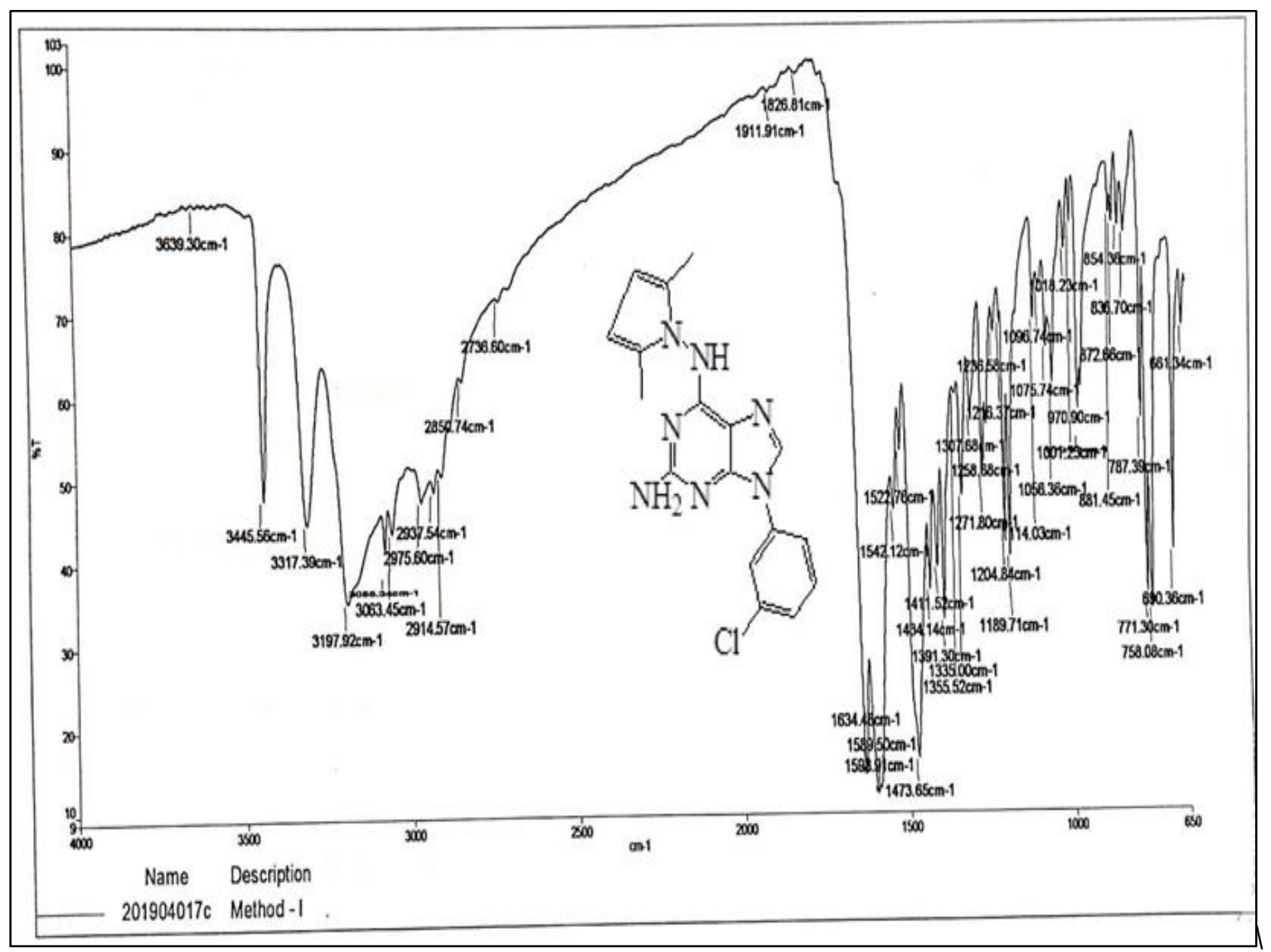

Fig 14: IR spectra of 9-(3-chlorophenyl)-N6-(2,5-dimethyl-1H-pyrrol-1-yl)-9H-purine-2,6-diamine

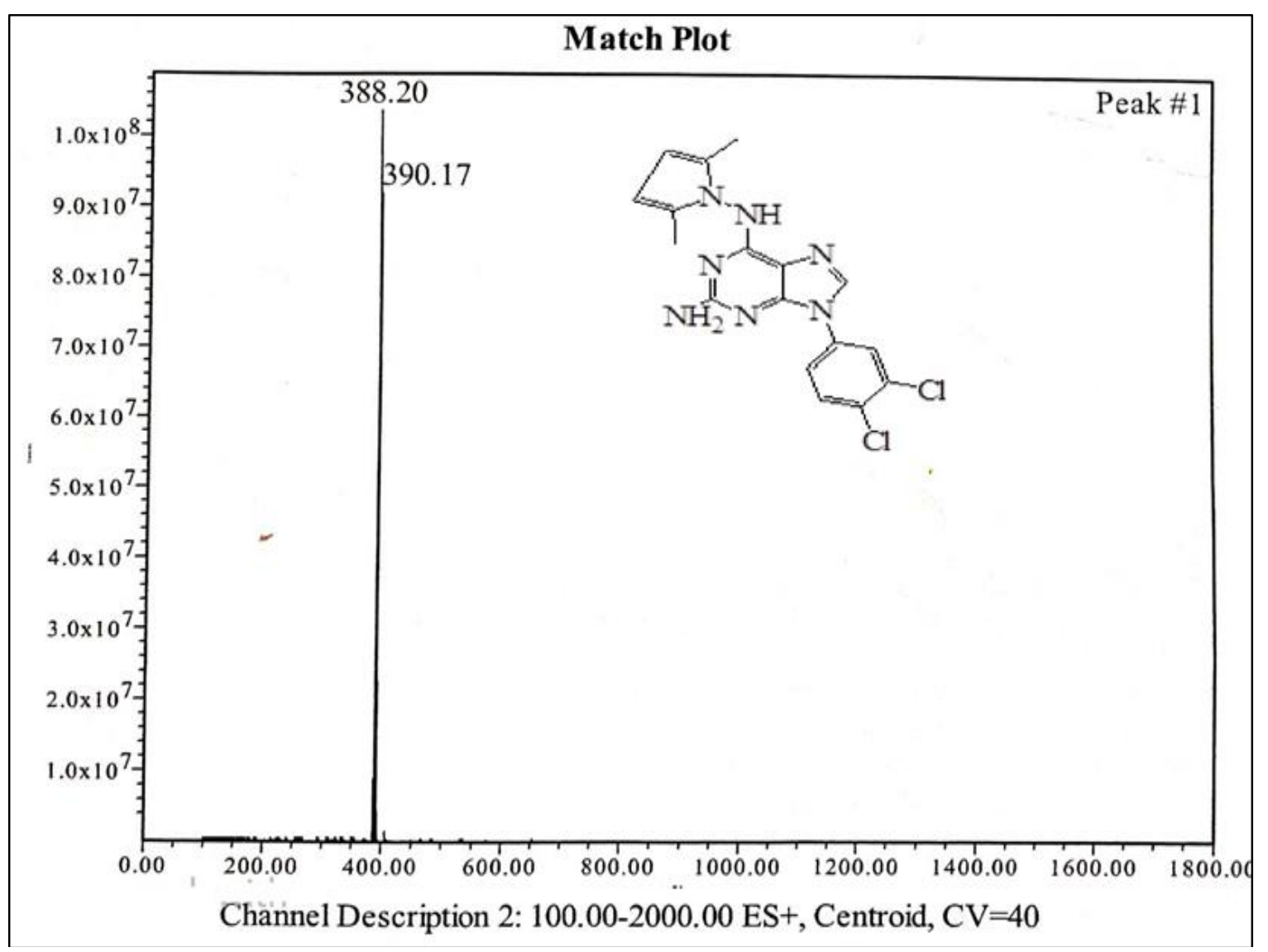

Fig 15: Mass spectra of 9-(3,4-dichlorophenyl)-N6-(2,5-dimethyl-1H-pyrrol-1-yl)-9H-purine-2,6-diamine 


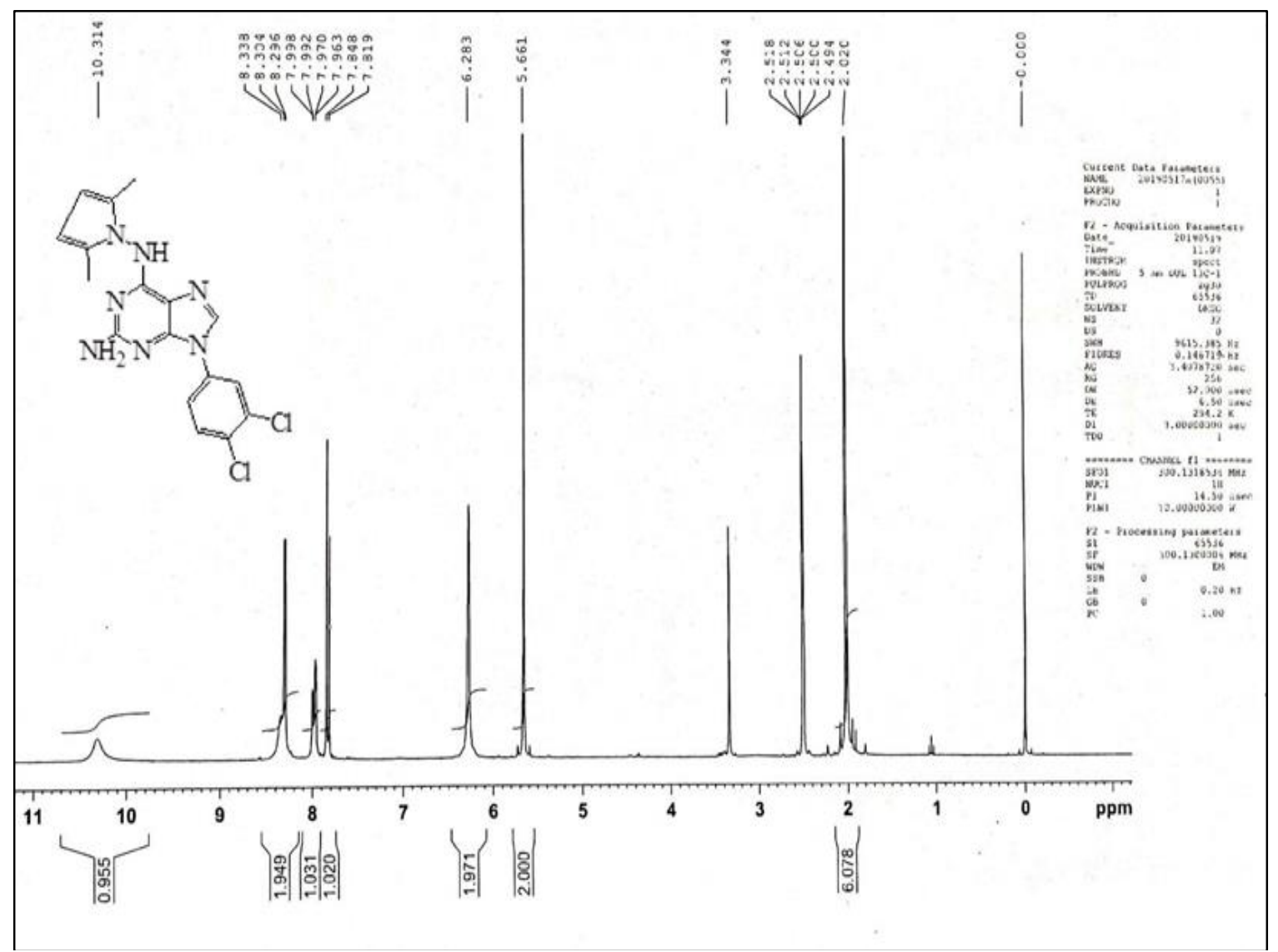

Fig 16: 1H NMR spectra of 9-(3,4-dichlorophenyl)-N6-(2,5-dimethyl-1H-pyrrol-1-yl)-9H-purine-2,6-diamine

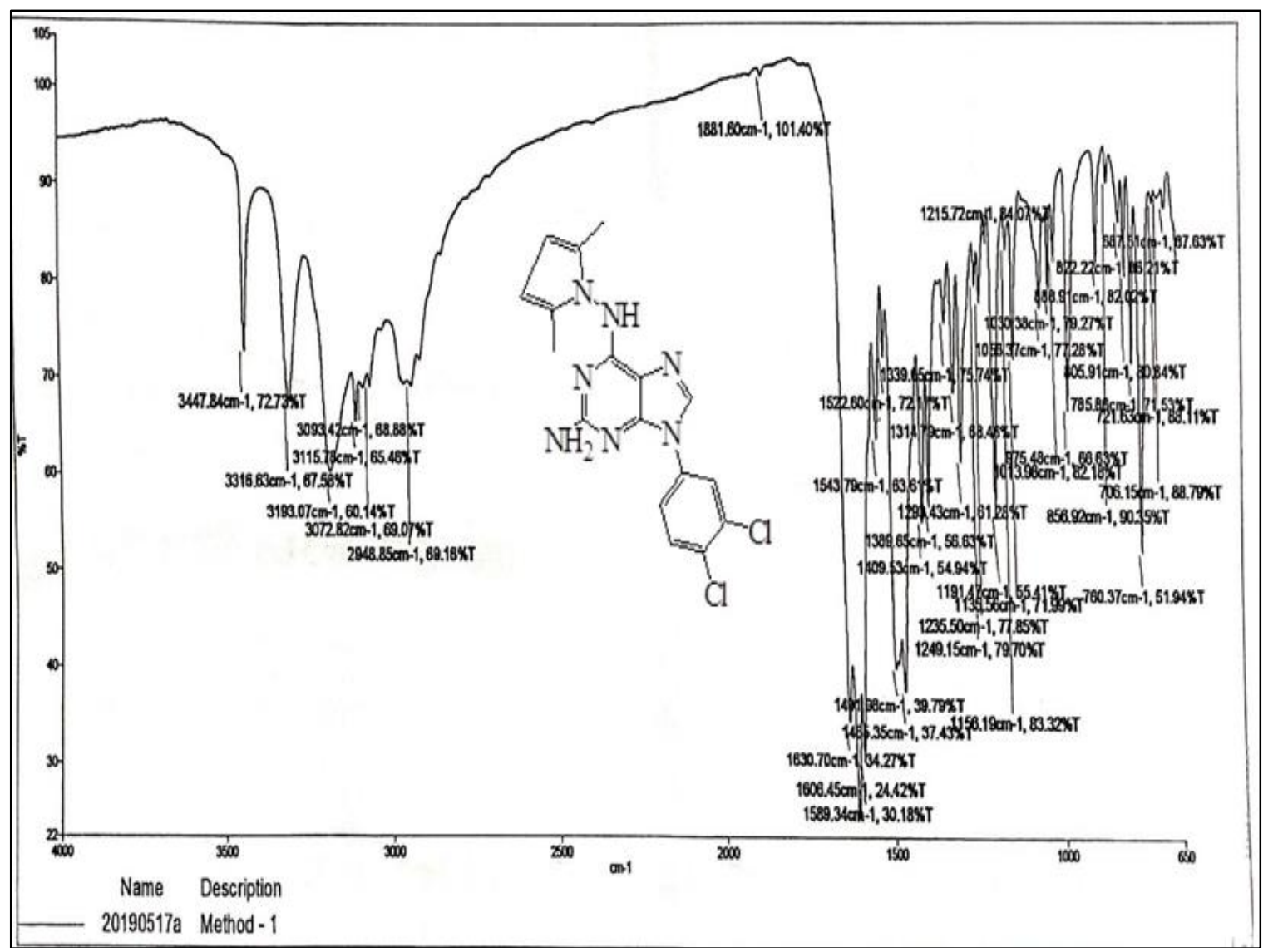

Fig 17: IR spectra of 9-(3,4-dichlorophenyl)-N6-(2,5-dimethyl-1H-pyrrol-1-yl)-9H-purine-2,6-diamine 


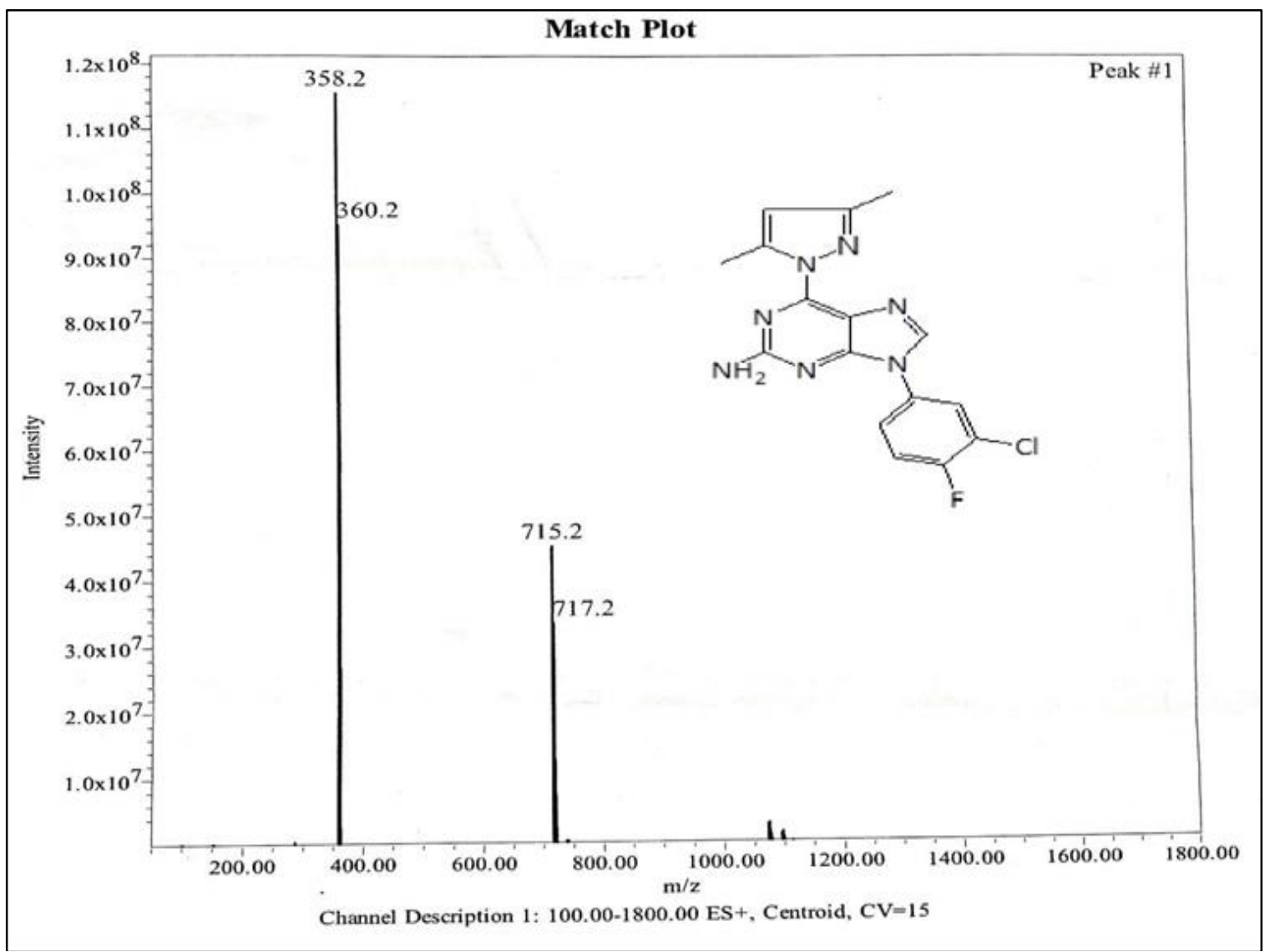

Fig 18: Mass spectra of 9-(3-chloro-4-fluorophenyl)-6-(3,5-dimethyl-1H-pyrazol-1-yl)-9H-purin-2-amine

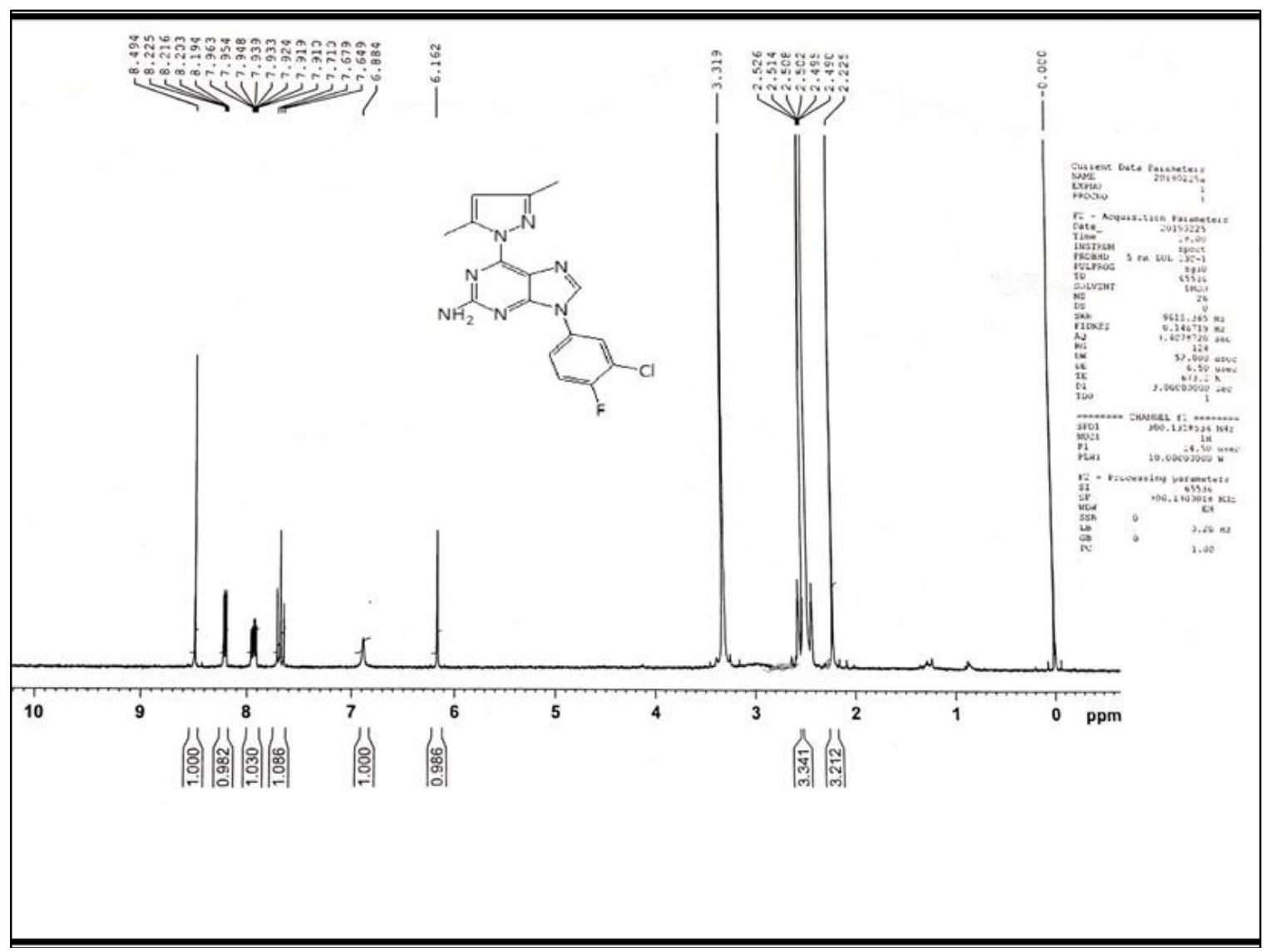

Fig 19: 1H NMR spectra of 9-(3-chloro-4-fluorophenyl)-6-(3,5-dimethyl-1H-pyrazol-1-yl)-9H-purin-2-amine 


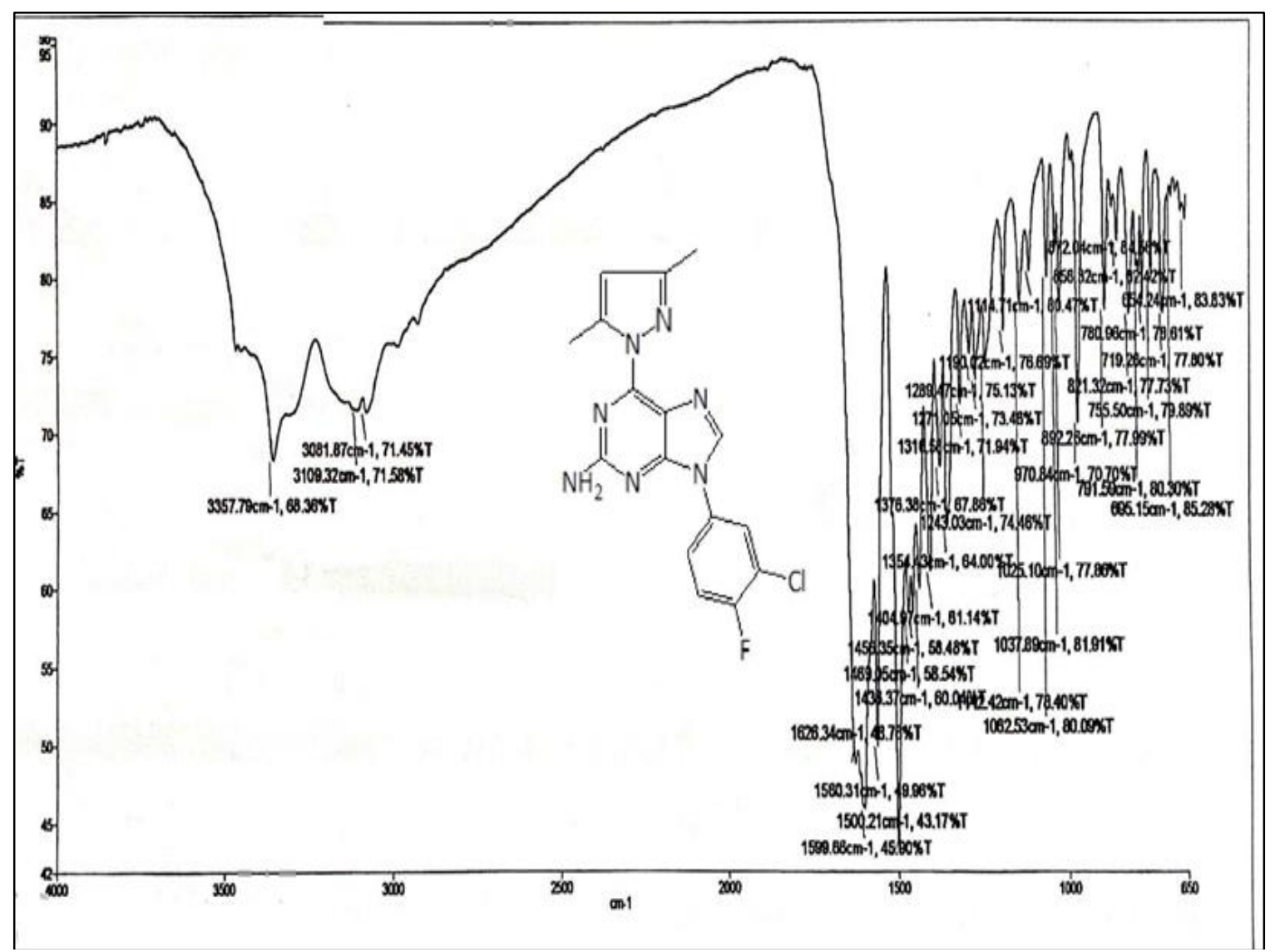

Fig 20: IR spectra of 9-(3-chloro-4-fluorophenyl)-6-(3,5-dimethyl-1H-pyrazol-1-yl)-9H-purin-2-amine

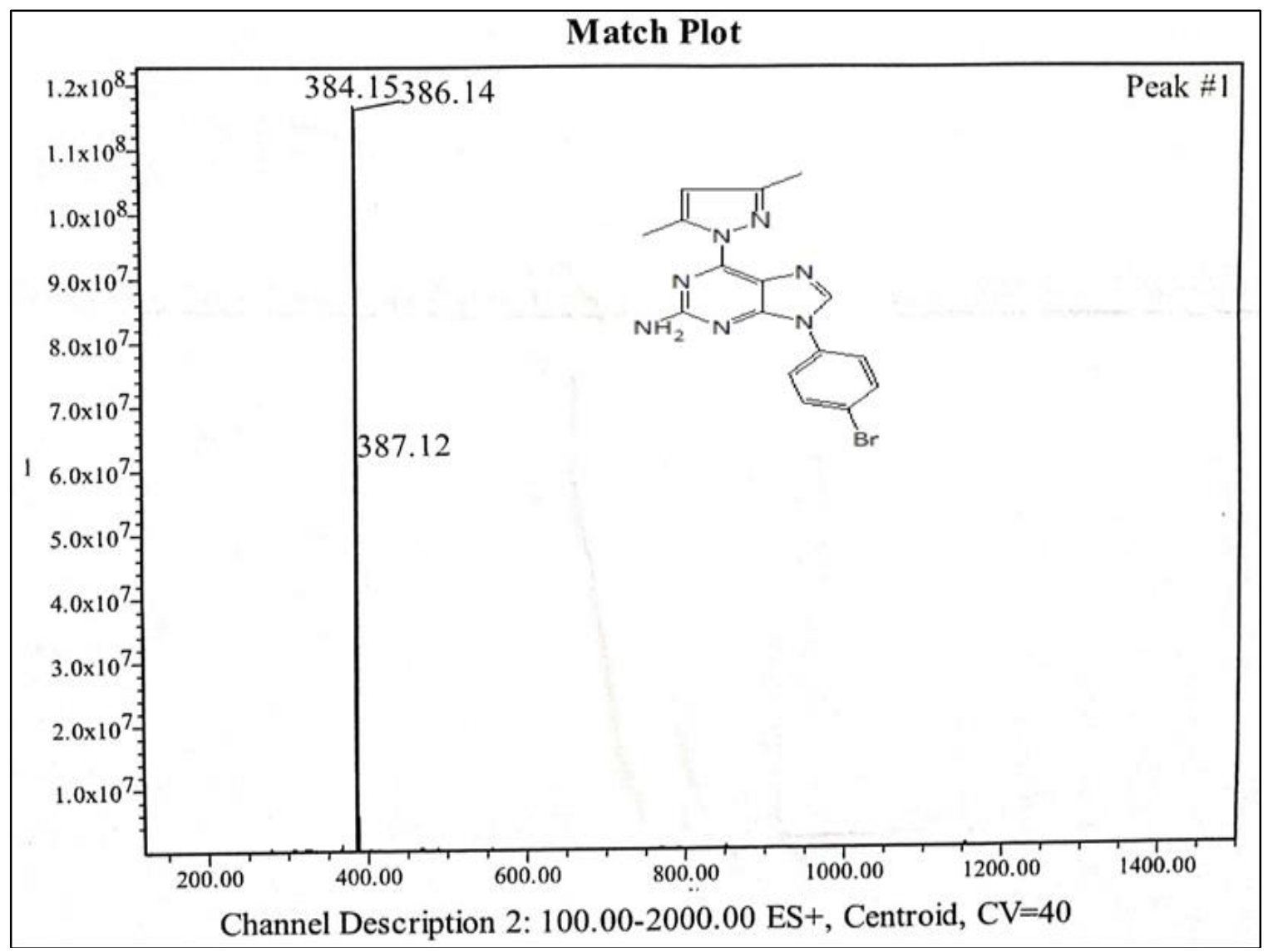

Fig 21: Mass spectra of 9-(4-bromophenyl)-6-(3,5-dimethyl-1H-pyrazol-1-yl)-9H-purin-2-amine 


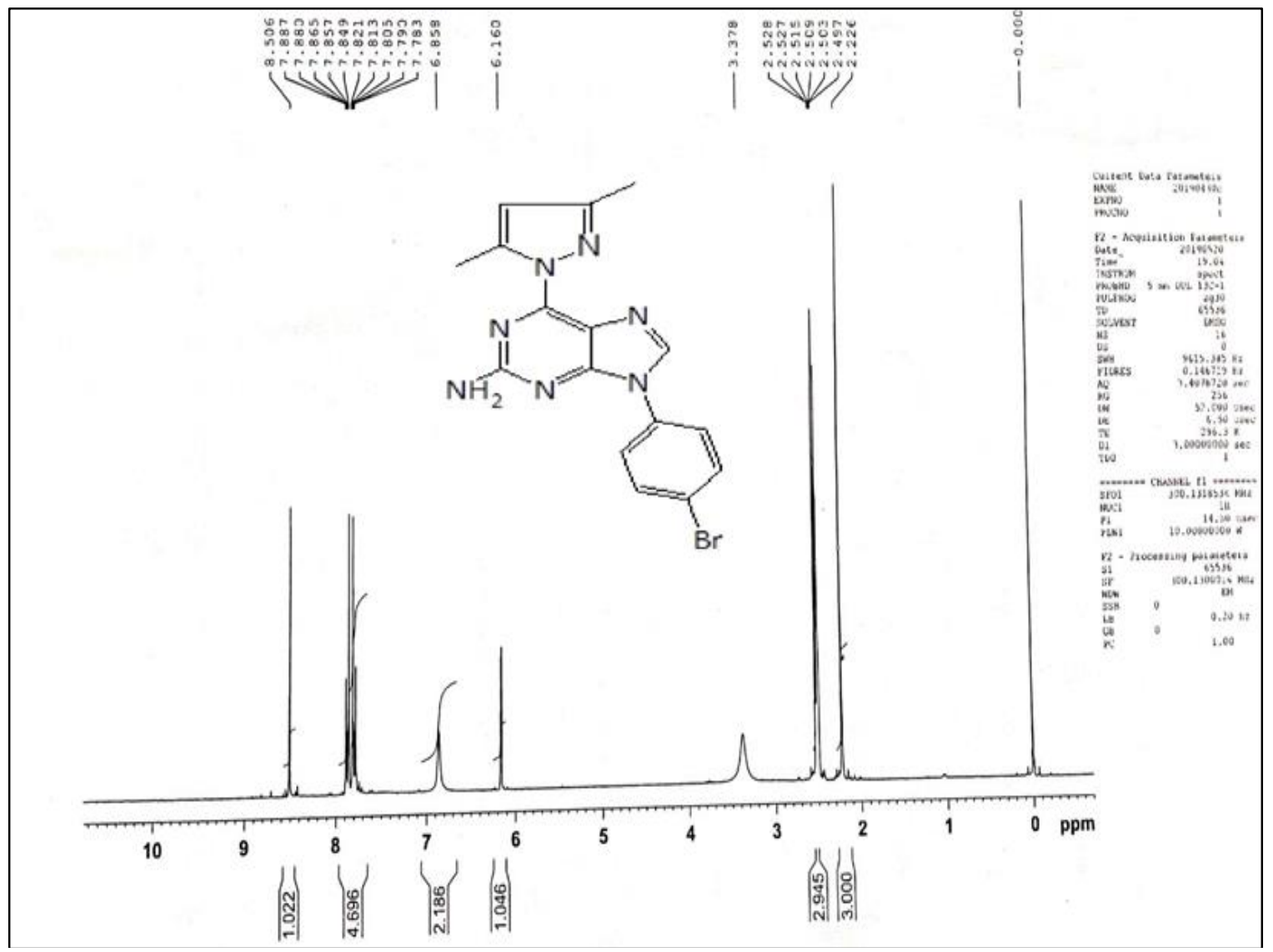

Fig 21: 1H NMR spectra of 9-(4-bromophenyl)-6-(3,5-dimethyl-1H-pyrazol-1-yl)-9H-purin-2-amine

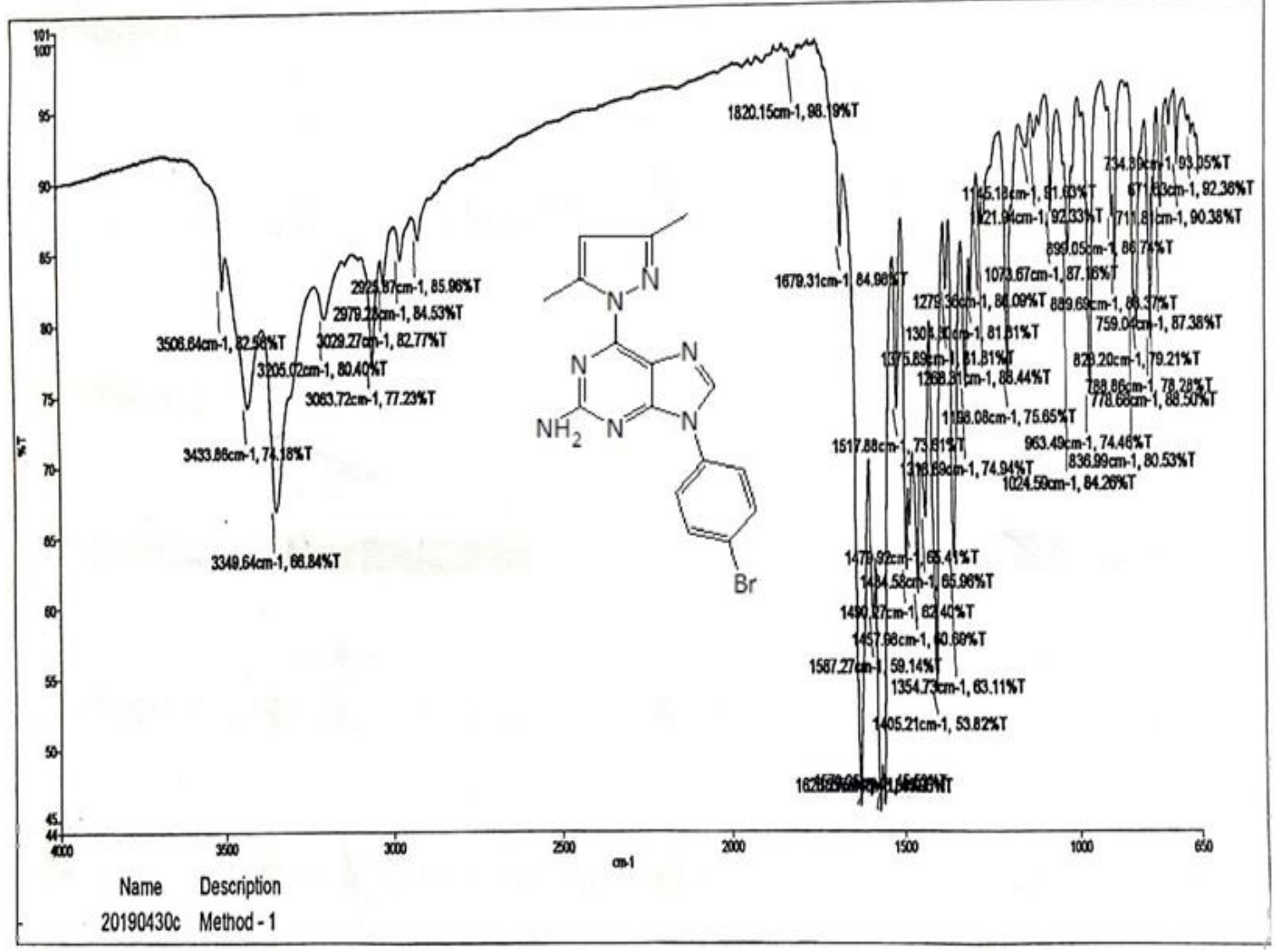

Fig 22: IR spectra of 9-(4-bromophenyl)-6-(3,5-dimethyl-1H-pyrazol-1-yl)-9H-purin-2-amine 


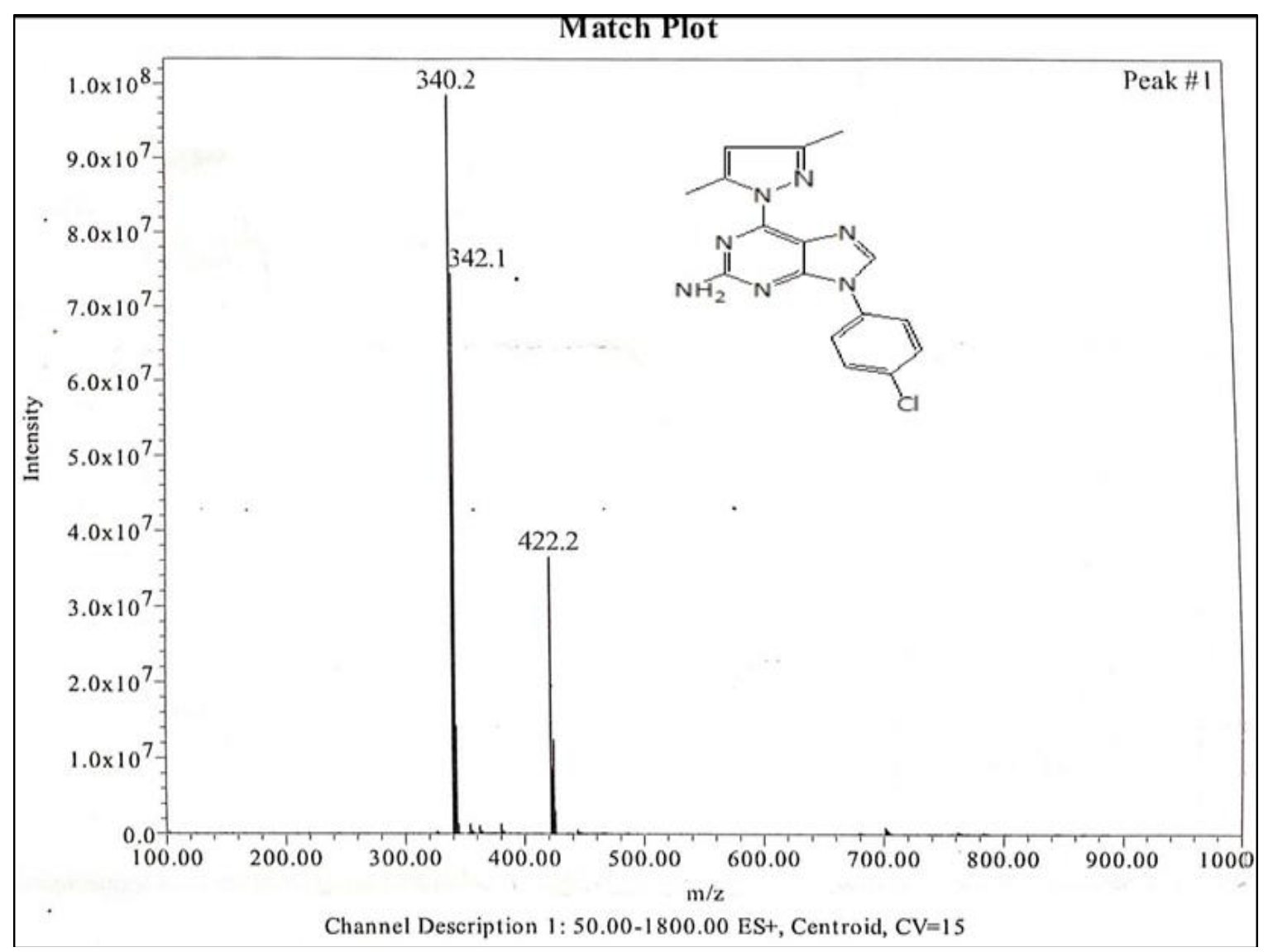

Fig 23: Mass spectra of 9-(4-chlorophenyl)-6-(3,5-dimethyl-1H-pyrazol-1-yl)-9H-purin-2-amine

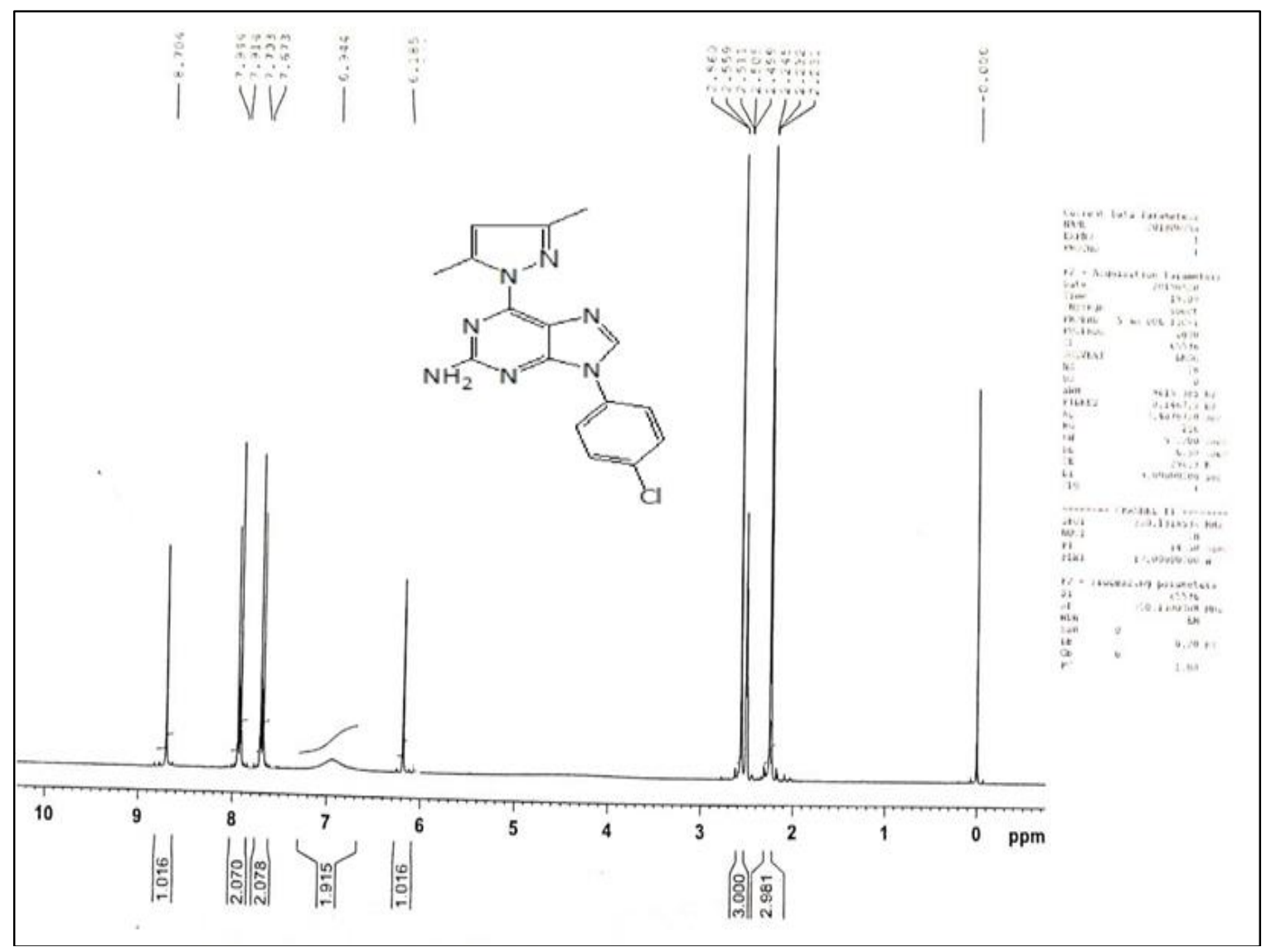

Fig 24: 1H NMR spectra of 9-(4-chlorophenyl)-6-(3,5-dimethyl-1H-pyrazol-1-yl)-9H-purin-2-amine 


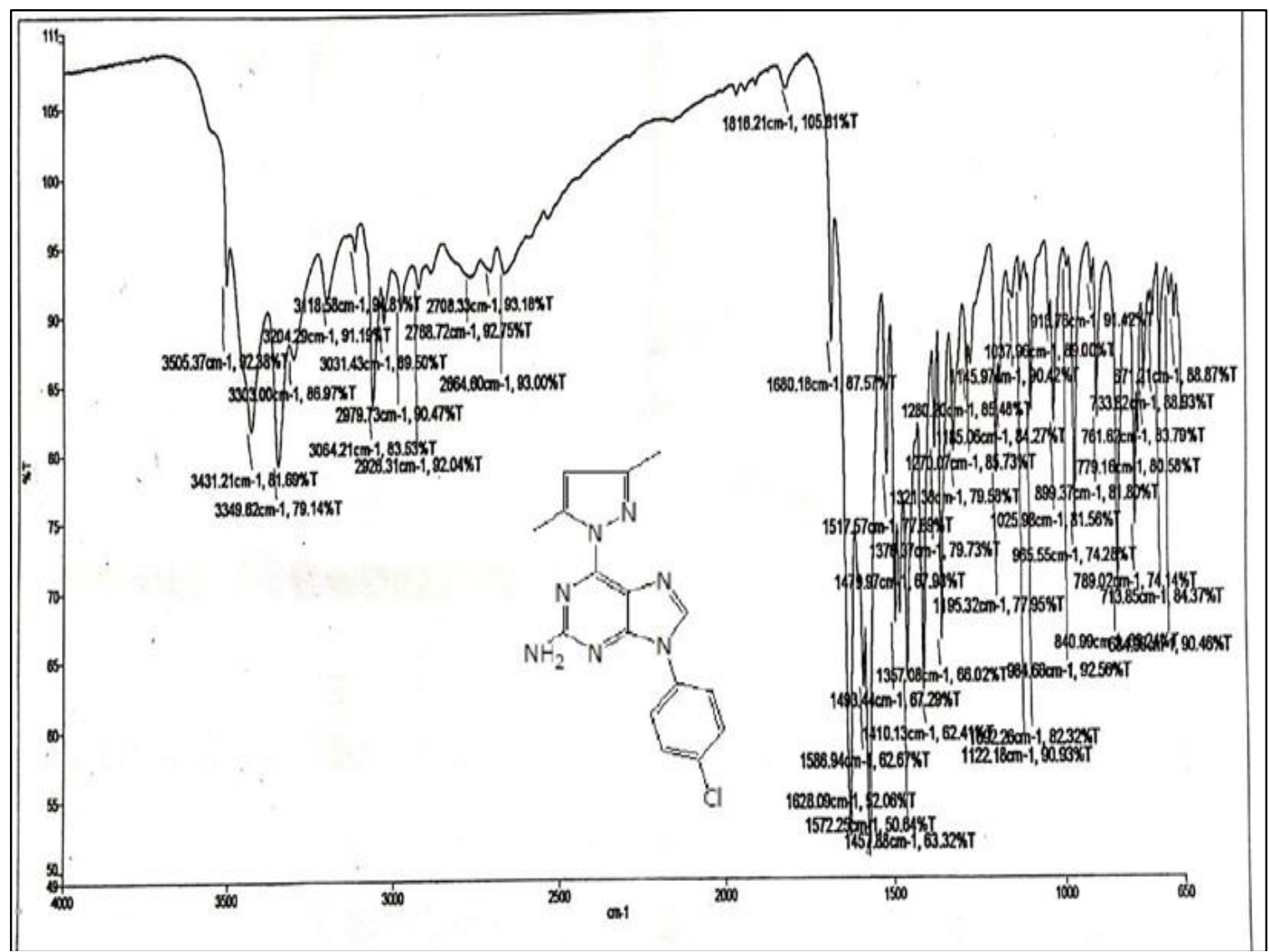

Fig 25: IR spectra of 9-(4-chlorophenyl)-6-(3,5-dimethyl-1H-pyrazol-1-yl)-9H-purin-2-amine

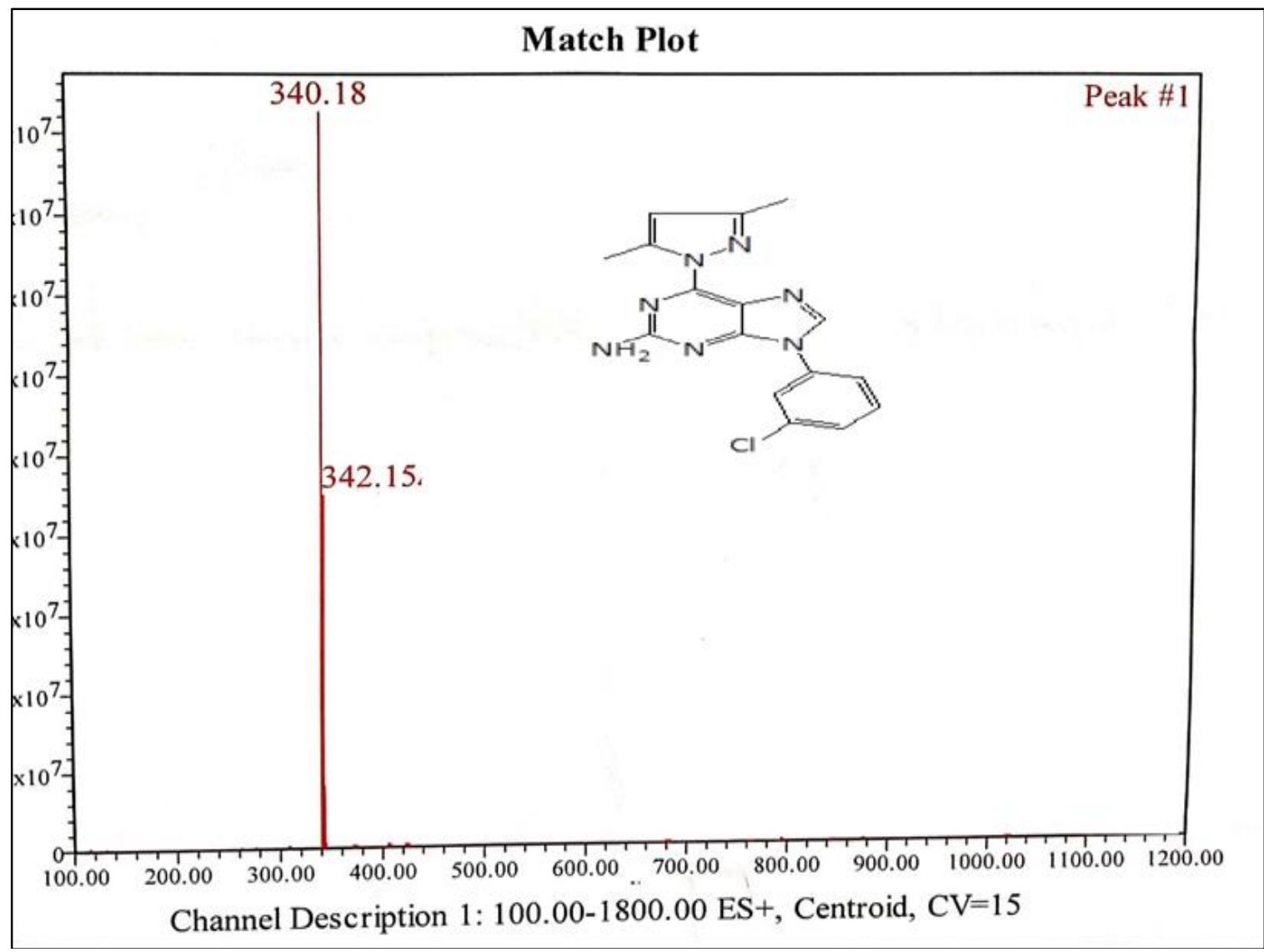

Fig 26: Mass spectra of 9-(3-chlorophenyl)-6-(3,5-dimethyl-1H-pyrazol-1-yl)-9H-purin-2-amine 


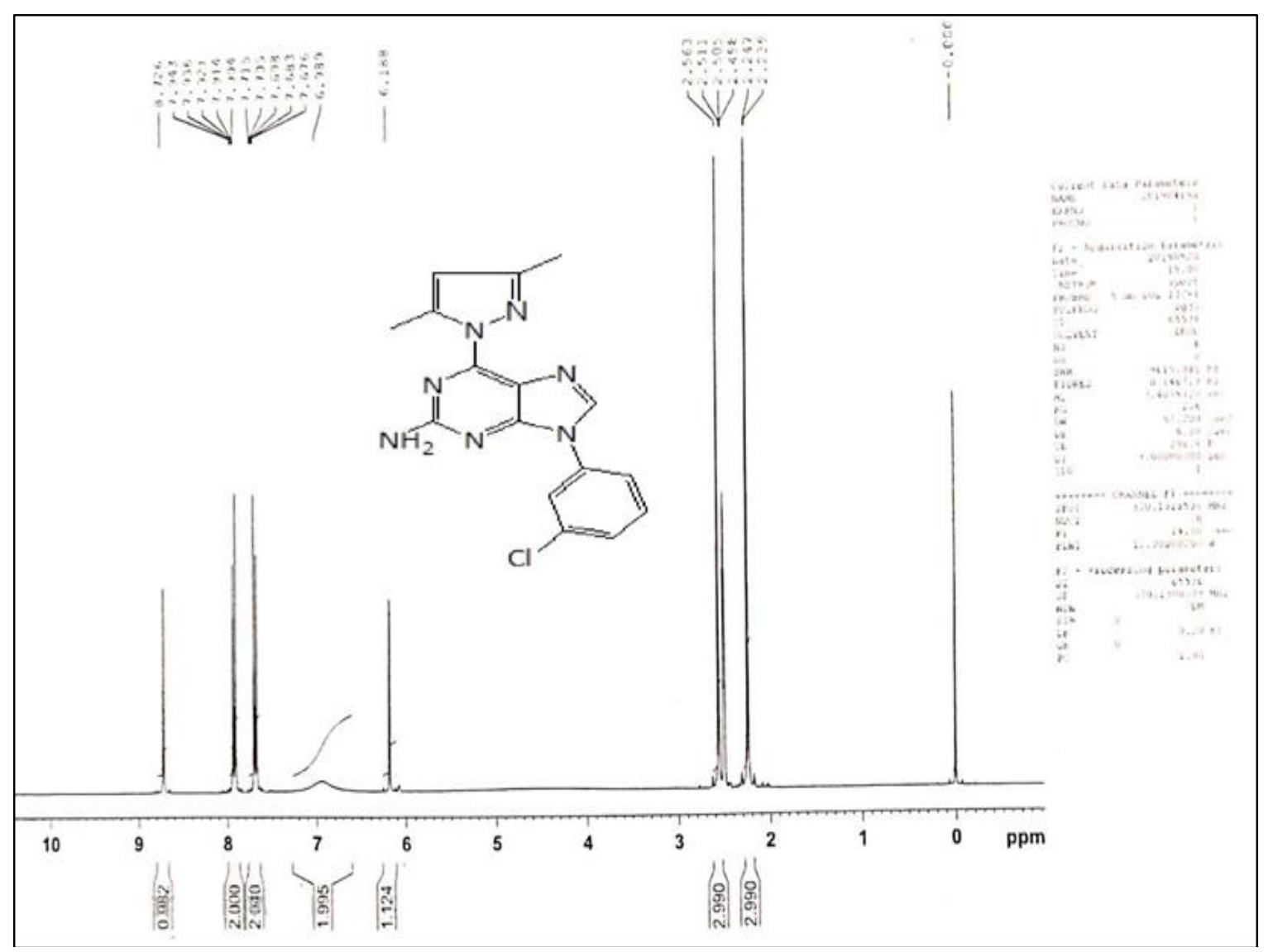

Fig 27: 1H NMR spectra of 9-(3-chlorophenyl)-6-(3,5-dimethyl-1H-pyrazol-1-yl)-9H-purin-2-amine

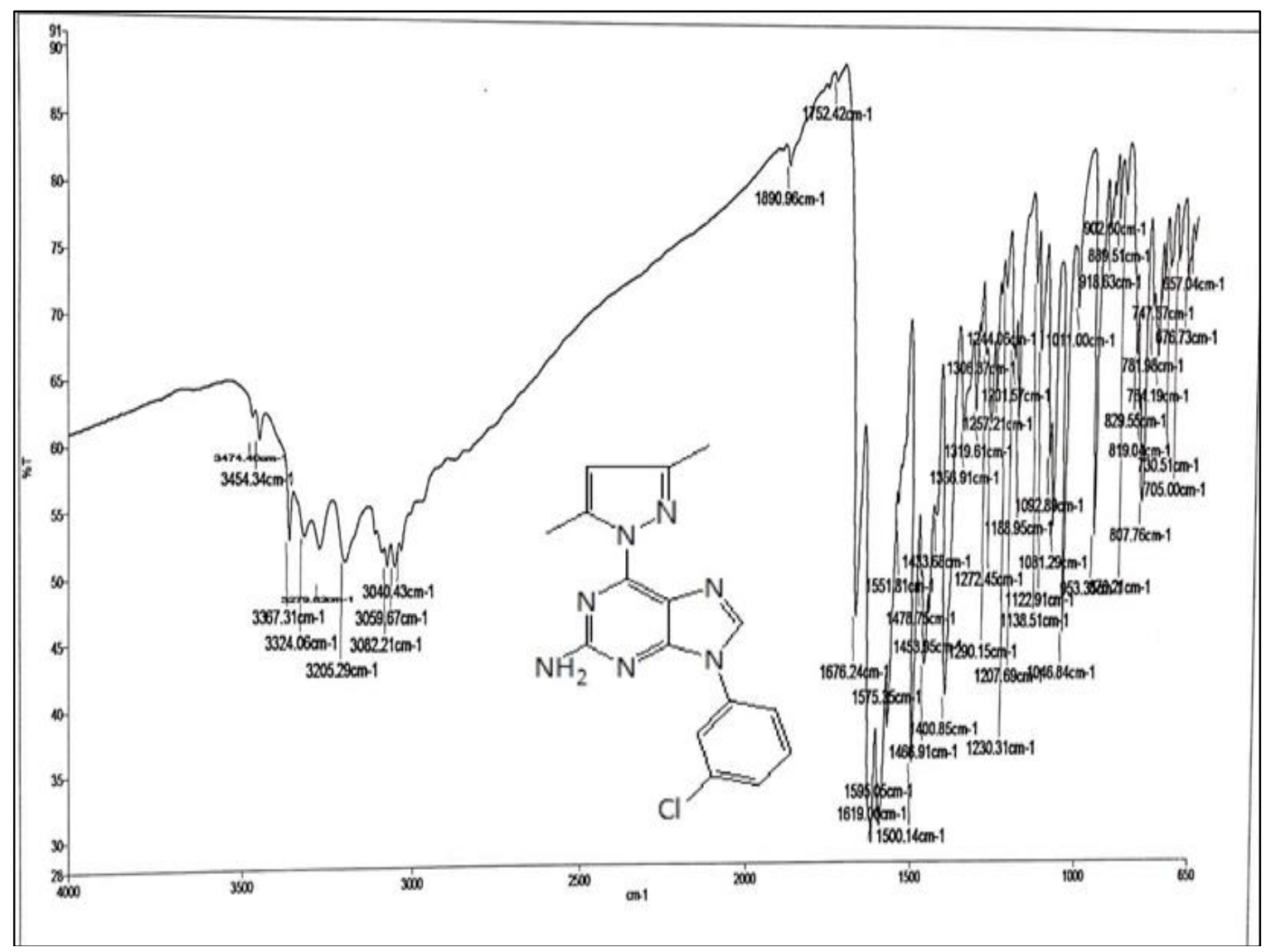

Fig 28: IR spectra of 9-(3-chlorophenyl)-6-(3,5-dimethyl-1H-pyrazol-1-yl)-9H-purin-2-amine 


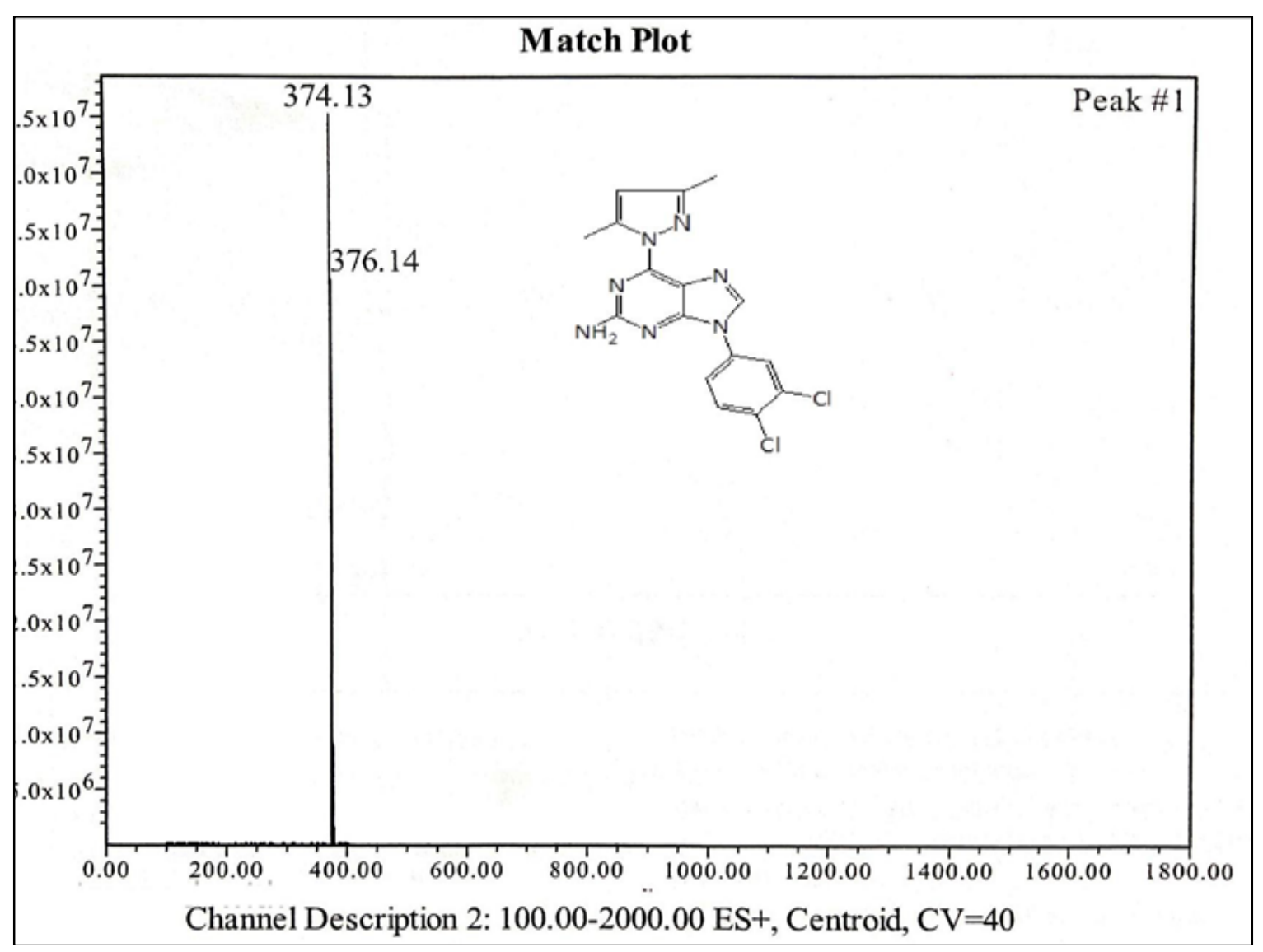

Fig 29: Mass spectra of 9-(3,4-dichlorophenyl)-6-(3,5-dimethyl-1H-pyrazol-1-yl)-9H-purin-2-amine

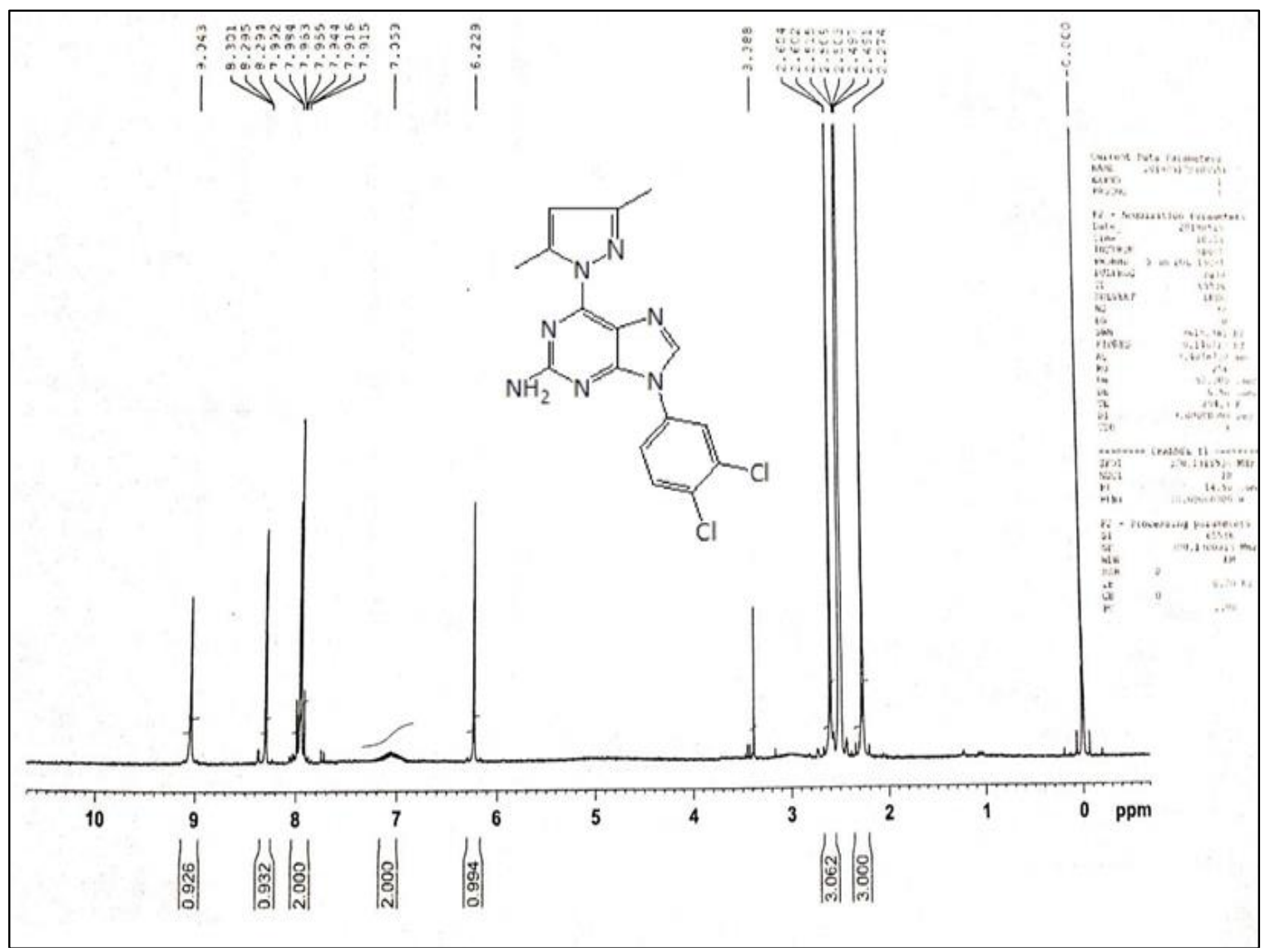

Fig 30: 1H NMR spectra of 9-(3,4-dichlorophenyl)-6-(3,5-dimethyl-1H-pyrazol-1-yl)-9H-purin-2-amine 


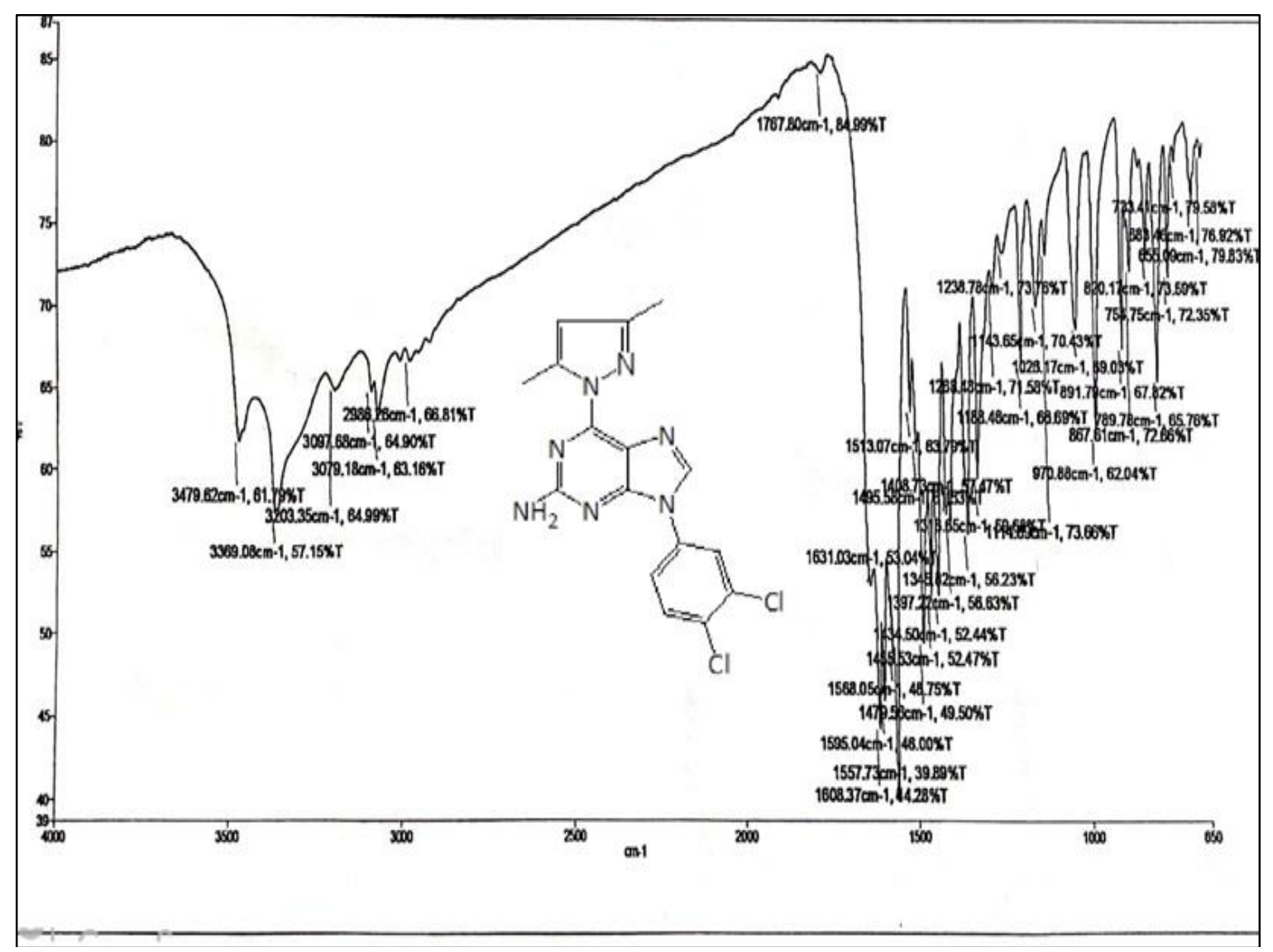

Fig 31: IR spectra of 9-(3,4-dichlorophenyl)-6-(3,5-dimethyl-1H-pyrazol-1-yl)-9H-purin-2-amine

\section{Conclusion}

A new series of aryl substituted purine derivatives were synthesized, the structure of these compounds was confirmed by IR, $1 \mathrm{H} \mathrm{NMR}$ and MS spectral data. The molecular docking study of newly synthesized pyrrole and pyrazole derivatives of purine reveals that all the compounds are having good interaction in favourable pose with gastrotropin protein. Pyrazole derivatives showed good affinity when compared to pyrrole derivatives. Few pyrazole derivatives (compounds $6,7,10$ ) showing better activity than standard drug abacavir which indicates these can be used as lead compounds for further development.

\section{Acknowledgements}

The authors are thankful to Laurus labs Ltd (Hyd) for providing facilities to do this work and also thankful to JNT University authorities for providing facilities, Anantapur. The authors are thankful to Mr. Jayasimha Rayalu for supporting to do docking studies in time.

\section{References}

1. Thalassitis A, Katsori AM, Dimas K, Dimitra J, Litina $\mathrm{H}$, Pyleris $\mathrm{F}$ et al. Synthesis and biological evaluation of modified purine homo-N-nucleosides containing pyrazole or 2-pyrazoline moiety. J Enzyme Inhib Med Chem. 2014; 29(1):109-117.

2. Omaima G, Razik HA, Shams ED, Ashour FA, Alaa AE, Ola SA et al. Purines and triazolo[4,3-e]purines containing pyrazole moiety as potential anticancer and antioxidant agents. Future Med Chem. 2018; 10(12):1449-1464.

3. Mousad M, Rashad AE, Zaki MA, Fathal S. Synthesis and antimicrobial screening of some fused heterocyclic pyrroles, Acta Pharm. 2005; (55):237-249.
4. Qian X, Liang GB, Feng D et al. Synthesis and SAR studies of diarylpyrrole anticoccidial agents. Bioorganic Med Chem Lett. 2006; 16(10):2817-21.

5. Liang G, Qian X, Biftu T et al. Hydroxylated N-alkyl4-piperidinyl-2, 3-diarylpyrrole derivatives as potent broad-spectrum anticoccidial agents. Bioorganic Med Chem Lett. 2015; 15:4570-4573.

6. Joseph M, Stefan H, Jack A, Paul C, Gary FC, James C et al. Synthesis and anti-inflammatory activity of 5Aroyl-1, 2-dihydro-3H-pyrrol [1, 2- $\alpha]$ pyrrole-1carboxylic acid and related compounds. J Med Chem. 1985; 28(8):1037-49.

7. Rooks WH, Tomolonis AJ, Maloney PJ, Wallach MB, Schuler ME. The analgesic and anti-inflammatory profile of ( \pm )-5-carbixylic acid. Agents and actions. 1982; 12(5):684-90.

8. Koyama M, Ohtani N, Kai F, Moriguchi I, Inoyue S. Synthesis and quantitative structure- activity relationship analysis of N-triiodoallyl and $\mathrm{N}$ iodopropargylazoles. New antifungal agents. J Med Chem. 1987; 30(3):552-62.

9. Kowalska A, Pluta K, Latocha M. Synthesis and anticancer activity of multisubstituted purines and xanthines with one or two propynylthio and aminobutynylthio groups. Medicinal Chemistry Research. 2018; 27:1384-1395.

10. Kowalska A, Latocha M, Pluta M. Synthesis and anticancer activity of thiosubstituted purines. Medicinal Chemistry Research. 2015; 24:3107-3116

11. Vinay Kumar L, Jagan Nai KP, Chandrasekhar T, Babul Reddy A, Karuna Sree M, Penchalaiah N et al. Synthesis, characterisation of some derivatives of 3-[(4chlorophenyl) sulfonyl] propane hydrazideDer Pharma Chemica. 2012; 4(2):674-678. 